\title{
Systematic Review: Controlled Trials of Interventions to Improve Communication in
} Intensive Care

By

\author{
Leslie P. Scheunemann
}

\begin{abstract}
A Master's Paper submitted to the faculty of the University of North Carolina at Chapel Hill in partial fulfillment of the requirements for the degree of Master of Public Health in the Public Health Leadership Program
\end{abstract}

Chapel Hill

2011

Advisor

Second Reader

Date 
Word Count-Abstract: 250

Word Count-Body: 3458

\section{Systematic Review: Controlled Trials of Interventions to Improve Communication in Intensive Care}

Leslie P. Scheunemann, MD¹, Michelle McDevitt, RN, BSN², Shannon Carson, MD ${ }^{2,3}$, Laura C. Hanson, MD, MPH ${ }^{1,4,5}$

All work on this manuscript was performed at the University of North Carolina at Chapel Hill.

This work was supported by the Hartford Center of Excellence in Geriatric Medicine and Training.

Dr. Scheunemann has no conflicts of interest to disclose. Ms. McDevitt has no conflicts of interest to disclose. Dr. Carson has no conflicts of interest to disclose. Dr. Hanson has no conflicts of interest to disclose.

IRB approval was not obtained for this research because it did not involve human subjects.

Correspondence:

Leslie P. Scheunemann, MD

Division of Geriatric Medicine

CB 7550

University of North Carolina

Chapel Hill, NC 27599-7550

${ }^{1}$ Division of Geriatric Medicine and Center for Aging and Health, University of North Carolina Hospitals, Chapel Hill, NC

${ }^{2}$ Medical Intensive Care Unit, University of North Carolina Hospitals, Chapel Hill, NC

${ }^{3}$ Division of Pulmonary and Critical Care Medicine, University of North Carolina Hospitals, Chapel Hill, NC

${ }^{4}$ Palliative Care Program, University of North Carolina, Chapel Hill, NC

${ }^{5}$ Cecil B. Sheps Center for Health Services Research, University of North Carolina, Chapel Hill, $\mathrm{NC}$ 


\section{Abstract}

Background: Communication between families and providers in the intensive care unit (ICU) affects patient and family outcomes, and healthcare utilization. Recent research has tested interventions designed to improve communication quality and outcomes between providers and families of ICU patients. We conducted a systematic review of these studies.

Methods: We searched MEDLINE, PsychInfo, Cochrane, and CINAHL from 1995 to July 2010. Included studies reported controlled clinical interventions designed to improve communication between providers and families of ICU patients aged 18 years or older. Investigators abstracted all selected studies to a standardized data collection instrument and completed a quality checklist based on recommendations from the CONSORT investigators.

Results: 2841 titles were identified. 180 met criteria for full review and 21 articles of 16 distinct interventions met full inclusion criteria, of which 5 were randomized. Interventions studied included printed information, or structured family conferences with or without additional family support. Conferences aimed to communicate diagnosis and prognosis, elicit patient values, assess family understanding, and clarify goals of treatment. Printed information, palliative care or ethics consultation, or regular, structured communication by the usual ICU team reduced family distress, improved comprehension, and decreased use of intensive treatments.

Conclusions: Moderate quality evidence supports printed information and structured communication by the usual ICU team, ethics consultation, or palliative care consultation to improve family emotional outcomes, and reduce ICU lengths of stay and treatment intensity. Evidence that these interventions reduce total costs is inconclusive. A comprehensive research agenda should ensure future study of a full range of patient-centered outcomes. 


\section{Introduction}

Communication between families and providers in the Intensive Care Unit (ICU) includes sharing information about illness and prognosis, engaging families in treatment decisionmaking, and offering support. ${ }^{1}$ Treatment decisions are complex, and communication is essential for designing treatments that incorporate patient values. Communication also affects patient and family outcomes. ${ }^{1-4}$ Therefore, ensuring high-quality family communication is a priority for clinicians, professional societies, regulatory bodies, and third party payers. ${ }^{5-7}$

However, communication is complicated by time constraints, lack of communication skills training, unclear goals and processes, and challenging family dynamics. Current ICU communication is often inconsistent, insufficient, and of poor quality. ${ }^{8,9}$ Families consider daily communication of clearly understandable information to be highly important, yet they rarely perceive adequate communication. ${ }^{8}$ As a consequence, patients' unique values and preferences may often not be respected, and resource-intensive treatments prolong the dying process for many.

In response to a demonstrated need to improve communication with families, ${ }^{10}$ investigators have tested a variety of innovative approaches using the methods of health services and communication research. In order to guide clinicians in maximizing the efficiency and effectiveness of communication, and to better define directions for future research, we conducted a systematic review to answer the following questions: in clinical trials testing interventions to improve family communication in the adult intensive care unit setting 1) are interventions effective in improving patient or family-centered outcomes? and 2) are interventions effective in reducing costs or resource use? 


\section{Methods}

\section{Data Sources and Searches}

This systematic review includes published randomized or non-randomized controlled trials reporting on interventions to improve communication between providers and family members. Because the landmark publication of the Study to Understand Prognosis and Preferences for Outcomes and Risks of Treatment (SUPPORT) ${ }^{11}$ in 1995 caused fundamental changes in communication about end-of-life treatment and decision-making, we excluded research printed before this study. We searched the MEDLINE, PsychInfo, Cochrane, and CINAHL databases from 1995 through July 19, 2010 for English-language articles reporting original data using the search terms "intensive care unit" or "critical care," plus "communication" or "decision making," plus "family," "husband," "wife," "son," "daughter," child," "parent," or "spouse”. We handsearched reference lists and drew from our personal files. A research librarian at the University of North Carolina Health Sciences Library assisted formulation of the search strategy.

\section{Study Selection}

Two unblinded authors independently reviewed all titles and abstracts identified by the search and excluded abstracts of articles that were about non-ICU or non-adult populations, reported review or observational studies, did not address communication, or addressed communication about organ donation. All remaining articles underwent full review.

In the full review we retained articles meeting the following inclusion criteria: populations including ICU patients older than 18 years; randomized or nonrandomized controls; report of results of clinical interventions designed to improve communication about medical information between medical providers and patients or their families. When we identified multiple reports of different aspects of the same trial, we report them together. We allowed any outcome 
measures. Any disagreements about inclusion were resolved by discussion between the reviewers. We reviewed reference lists of accepted articles for additional studies.

\section{Data Extraction and Quality Assessment}

We abstracted the selected articles using a standardized data collection instrument including study design, population, sources of bias from selection, measurement, or confounding, outcome measures, and results. We created a quality checklist by adapting recommendations from the CONSORT groups; ${ }^{12,13}$ this aligned well with the TREND criteria for non-randomized trials. $^{14}$ It included type of controls, determination of sample size, clarity of participant flow, blinding, prespecification of outcome measures, use of validated measurement tools, adherence to the intervention, and handling of missing data (Table 1). Two reviewers independently completed the quality checklist for each study; there were few disagreements, and all were resolved by consensus.

\section{Data Synthesis and Analysis}

For analysis purposes, we divided interventions described in these studies into those which utilized printed information, required an additional specialty provider or team, and those which relied on existing ICU personnel (physicians, nurses, and social workers). We characterized outcome measures as patient-and-family-centered, such as satisfaction and emotional outcomes, or as outcomes related to cost or utilization of health care resources, such as use of nonbeneficial treatments or lengths of stay (LOS). We used the PRIMSA checklist for reporting systematic reviews during manuscript preparation to ensure transparency. ${ }^{15}$ 


\section{Results}

Of the initial 2841 titles identified by the search strategy, 168 met criteria for full review, and an additional 12 were identified from reference lists or our personal files. Of these 180 articles, 21 met all inclusion criteria representing 16 distinct interventions (Figure 1). Overall methodologic quality of studies varied (Table 1). All compared an intervention to a control group receiving usual care. Although two studies enrolled communicative patients as subjects, few patients participated and no studies reported outcomes of this communication. Patient populations varied from inclusion of all ICU patients, to subsets of patients at high risk for dying based on prolonged hospitalization or mechanical ventilation, severity of illness, or diagnosis, to the subset who died.

Some studies used printed information, with or without family conferences. Others focused on family conferences, with or without additional practical or palliative support. Although not all studies describe the conferences in detail, they generally consist of provider-family meetings, conducted early in the ICU stay, and focusing on communication of diagnosis, prognosis, and treatment options, elicitation of values and treatment decisions, and family support.

Because many outcome measures for satisfaction, communication, and decision-making are relatively unfamiliar, we have compiled them into tables and refer to the broad category of outcome assessed in the text (Tables 2 and 3).

\section{Trials investigating printed information}

Three trials, two of high quality, found that printed information could improve family comprehension and emotional outcomes, but perhaps not length of stay or satisfaction (Tables 4 and 5). In a 34-center RCT in France, ${ }^{16}$ simple provision of a Family Information Leaflet improved family comprehension for patients with expected ICU LOS > 48 hours (36 intervention 
families with good comprehension v. 10 controls, $p<0.0001$ ). It failed to change satisfaction or emotional distress. A 22-center French RCT coupled a bereavement brochure with proactive family conferences for patients with high likelihood of mortality and found significantly fewer post-traumatic stress symptoms 90 days after the patients' deaths $(p=0.02) .{ }^{17}$ The secondary outcome of depression and anxiety also improved for intervention families $(p=0.004)$. As attending physicians had judged included patients to be likely to die within a few days, the finding that LOS was unchanged was expected. One small pre-post study ${ }^{18}$ found that a nursing intervention including family meeting on admission, provision of an ICU booklet, and daily telephone updates did not affect overall family satisfaction, but enrollment of only 30 participants may have limited power.

\section{$\underline{\text { Randomized trials of interventions with ICU personnel }}$}

The 22-center French RCT above ${ }^{17}$ used printed information to supplement standardized family meetings ${ }^{1}$ delivered by ICU personnel. Family meetings used the VALUE principles: value and appreciate what families said, acknowledge family members' emotions, listen, ask questions about who the patient was as a person, and elicit questions from family. This intervention improved family post-traumatic stress, anxiety, and depression 90 days after patients' death, without changes in satisfaction or LOS. Fewer non-beneficial treatments were provided to the intervention group. The two portions of the intervention are likely synergistic as this trial demonstrated improved emotional outcomes not seen in the study of printed information alone.

Three articles reported a communication-intensive palliative care quality improvement initiative for patients dying in the ICU or within 30 hours of transfer from the ICU. ${ }^{19,20,21}$ The intervention included provider training and feedback, rather than direct intervention with families. In the prepost design pilot study, the primary outcome of family-rated communication and palliative care did not change (response rate $55 \%, p=0.09$ ), but nurse-rated communication and palliative care 
improved (response rate 68\%, $\mathrm{p}<0.01$ ) while ICU LOS decreased $(7.2$ v. 5.8 days, $p<0.01){ }^{19}$ Social workers increased communication with families about spiritual needs, addressed interfamily decisional conflict, helped families know it was okay to talk to or touch a loved one, and assured families of aggressive symptom management. ${ }^{21}$ Investigators then implemented the intervention in a separate investigation of a well-conducted 12-center, cluster-randomized $\mathrm{RCT}^{20}$ It failed to demonstrate improved indices of family or nurse ratings of quality of communication or palliative care. Outcome ascertainment was incomplete due to response rates of no more than $50 \%$. Family conferences within the first 72 hours actually decreased during the study $(p<0.001)$.

\section{$\underline{\text { Randomized trials of ethics consultation }}$}

Schneiderman performed first a single-site $\mathrm{RCT}^{22}$ followed by a 7-center $\mathrm{RCT},{ }^{23}$ evaluating the offer of ethics consultation for patients with value-laden treatment conflicts. In the initial study, there were 21 decedents in each group, and those receiving ethics consultation demonstrated significant decreases compared to usual care in the number of days in the ICU (13.2 v. 4.2, $\mathrm{p}=0.03)$ and number of days using artificial nutrition/hydration (12.0 v. 4.1, $\mathrm{p}=0.05)$ and ventilator (11.4 v. 3.7, $\mathrm{p}=0.05)$ treatments. Use of other intensive treatments did not differ between groups. The second, 7-center study showed similar results: decedents in the intervention group had decreased hospital (8.66 v. 11.62, $p=0.01)$ and ICU (6.42 v. 7.86, $p=0.03$ ) lengths of stay, and fewer days receiving mechanical ventilation (6.52 v. 8.22, $p=0.03)$. There was no significant change in days of artificial nutrition and hydration. Patients surviving to hospital discharge did not have any significant differences in these outcomes. The intervention did not affect mortality. 


\section{Interventions with non-random controls}

\section{Ethics consultation}

A non-randomized trial with concurrent controls tested ethics consultation for patients mechanically ventilated for $>96$ hours. ${ }^{24}$ LOS decreased by six days, correlating with increased documentation of advance care planning (32.0\% at baseline, $38.7 \%$ in concurrent controls, $61.0 \%$ in intervention group $(\mathrm{p}<0.05))$ and increased withholding or withdrawal of life sustaining treatments $(18.9 \%$ of baseline, $22.6 \%$ of control, and $48.0 \%$ of intervention patients $(p<0.05))$. Unfortunately, this study found increased hospital mortality for the intervention patients $(67.7 \%$ vs. $43.2 \%$ baseline and $48.4 \%$ control, $p<0.05)$. Investigators speculated that differences in timing of death relative to discharge might explain this difference, but analysis were limited to deaths occurring in-hospital.

\section{Palliative care consultation}

Three trials suggested that palliative care consultation decreases patient LOS. Of the two better quality studies, the largest occurred in a trauma ICU and demonstrated decreased ICU and hospital LOS for patients who died $(\mathrm{p}<0.05)^{25}$; the second study showed decreased ICU LOS (8.89 v. 16.28 days, $p=0.0001$ ) for patients at high risk of dying without changes in hospital LOS. $^{26}$ The last included small numbers of historical controls and showed decreased ICU and hospital LOS for patients with end-stage dementia ${ }^{27}$ and global cerebral ischemia after cardiac arrest, but not for patients with multi-organ system failure. ${ }^{28}$ A small fifth study found palliative care consultation improved some domains of family satisfaction for families of patients who died, but response rates to the questionnaire were $<30 \%$, limiting its internal validity. ${ }^{29}$ 


\section{Other specialized personnel}

Two non-randomized interventions found conflicting results for patient LOS and costs when specially trained nurses facilitated communication. One study used the medical director as the attending physician of the intervention group, and demonstrated decreased hospital LOS (11.3 v. 16.4 days, $p=0.03)$, and lower direct and indirect costs $(\$ 15,559$ v. $\$ 24,080$ direct, $p=0.01$, and $\$ 5087$ v. $\$ 8035$ indirect, $p=0.007$ ) for patients at high risk of dying in a medical ICU. ${ }^{30} \mathrm{~A}$ second study enrolled patients expected to have $>5$-day postoperative stay in a trauma ICU and showed no change in LOS or costs. ${ }^{31}$ It also had low response rates to surveys, but showed some improvements in family satisfaction with communication. Sites of practice and target patients differed, but the exploratory nature of the studies likely accounts for some of the difference in outcomes.

\section{ICU personnel}

One non-randomized study showed no differences in family satisfaction for patients at high risk for decisional conflict in four surgical and three medical ICUs when social workers facilitated family communication, but data were missing for $>40 \%$ of patients. ${ }^{32}$ Investigators reported improved clarity of treatment goals, demonstrated by increased decisions to forego cardiopulmonary resuscitation (OR 1.81, $\mathrm{p}=0.017$ ), provide comfort measures only (OR 1.94, $\mathrm{p}=0.018$ ), and to treat aggressively (OR $2.30, p=0.002$ ), without changes in LOS. ${ }^{32}$

One intervention reported positive initial ${ }^{33}$ and long-term ${ }^{34}$ effects on resource utilization from implementation of regular, structured family meetings emphasizing clinical milestones by the medical ICU team. Median ICU LOS decreased overall from 4 to 3 days for both studies. Overall ICU mortality rates also decreased from $31.3 \%$ pre-intervention to as low as $18.0 \%$ at four-year follow-up $(p<0.001)$; investigators attributed this finding to earlier triage of the sickest 
patients who eventually died, which allowed increased ICU treatment of patients with lower acuity illness. A third pre-post study built on this model, but narrowed its focus to patients receiving $>72$ hrs of mechanical ventilation without expectation of extubation in the next 48 hours in 5 ICUs (medical, surgical, and neurosurgical). ${ }^{35}$ It failed to demonstrate differences in hospital or ICU LOS. Post-discharge mortality was higher for control patients.

One study investigated a formal weekday relatives' clinic held by ICU personnel for families of ICU patients; ${ }^{36} 40 \%$ of families utilized this clinic, and less than half of participants completed the outcome measure survey. It failed to demonstrated improved family satisfaction.

\section{Discussion}

Our systematic review of family-provider communication interventions for ICU patients includes 21 articles reporting results of 16 distinct interventions that are heterogeneous in intervention design, selection of control groups, and outcome measures. This evidence includes 5 randomized trials, and 7 non-randomized trials with other methodologic strengths. Despite this heterogeneity, several consistent themes emerged. Moderate quality evidence supports the provision of printed information to improve family comprehension. Moderate quality evidence also supports structured family conferences conducted by the usual ICU team, ethics consultation, or palliative care consultation to improve patient and family centered outcomes, including emotional distress, processes of communication, and the frequency and timing of decisions about major treatments.

Structured communication also reduced ICU LOS and intensity of treatment use, outcomes which measure resource utilization components, and which may also affect patients' experience of care. However there is debate about how much impact reductions in ICU LOS have on total hospital costs. ${ }^{37,38}$ which were not measured in most studies. More importantly, it is unclear if 
reduced ICU LOS leads to less prolonged dying, diminishes suffering for dying patients, or has other value for patients and families. Measuring these patient- or family-reported outcomes directly represents an important focus for future research.

Interventions had greater effects for patients who died than for those who lived, but did not increase the risk of dying itself. Thirteen of fourteen studies reporting mortality, the primary patient-centered outcome used in these studies, showed unchanged or decreased mortality rates after the intervention.

Specialized providers and usual ICU personnel are both able to implement communications interventions effectively, suggesting that consistent initiatives to communicate with families may be the most important element of successful provider-family communication. The content and structure of communication varied among studies, although one tested framework has been published. ${ }^{39-41}$ The VALUE mnemonic is one of the clearest frameworks for communication, although several other study communication protocols also provide useful conceptualizations. ${ }^{1,}$ $23,25,30,32,33$ Although helpful, these protocols do not delineate specific elements of communication that are critical to success, such as length of conferences, key providers to include, or content that increases comprehension or provides increased emotional support for families. Additionally, as high-quality observational studies reveal more about the ways physicians and families communicate, ${ }^{42-44}$ clinicians may be able to strengthen specific elements of the decision-making process, such as family comprehension of prognosis and treatment pathways, elicitation of patient values, participation in deliberation over treatment choices, or communication about norms of ICU care.

It appears likely that physician involvement is necessary for successful interventions. The extent of involvement required is uncertain, but the few interventions initiated by nurses, or led by social workers, were less likely to be successful. ${ }^{18,21,32}$ This conclusion must be accepted 
cautiously, as few such studies were conducted, and those were often characterized by low number of enrolled patients, or use of satisfaction instruments with low response rates as their primary outcome measures. Quality improvement research has clearly demonstrated the importance of strong local champions for success of interventions. ${ }^{45}$ Nurses and social workers may be able to wield these roles effectively as team approaches become more entrenched in local cultures and if families can come to expect and trust communication from non-physicians as authoritative. Future research may explore this possibility.

Several important considerations must influence the application of our study results. First, the provision of printed information is simple, efficient, and should probably be almost universally adopted. The Society of Critical Care Medicine, American College of Chest Physicians, American Thoracic Society and provide pamphlets at http://www.myicucare.org/Support Brochures/Pages/default.aspx, https://accp.chestnet.org/storeWA/StoreAction.do?method=view\&pcrNum=19, and http://patients.thoracic.org/information-series/. Second, local characteristics, including the availability of consultative services or ICU personnel who champion communication initiatives, should guide the selection of any particular strategy. Third, at present, most data support intensive communication for patients at high risk of dying; concentrating on these patients is an efficient use of clinician time but should not exclude other populations at risk, such as those suffering severe delirium or the chronically critically ill. Fourth, it appears uncertain that significant cost savings will be realized by any current interventions, and institutional planners must consider this when appropriating resources for ICU care.

A wide variety of outcome measures were tested in these studies, many of which were responsive to intervention. The evidence is reasonably strong that we can improve family comprehension, family emotional distress, reduce use of intensive treatments, and decrease 
lengths of stay. Although family satisfaction is an important aspect of quality care, response rates are low and interventions evaluating satisfaction should also investigate other outcomes.

Many ICU patients are incapable of consenting to or participating in research interviews. Few studies included in this review addressed patient-centered outcomes beyond mortality. Palliative care outcomes should continue to be a focus of future research. ${ }^{46,47}$ Additional proposed measures include symptom assessment and treatment; delirium assessment and treatment; elicitation of values; assessment and attention to the emotional, spiritual, and practical needs of patients and their families; and emotional and organizational support for ICU clinicians. ${ }^{46,47}$ Other outcomes that may be important include complicated family grief, family return to work, financial impact of illness on patient and family, and compassion fatigue among clinicians. Although improved allocation of resources in the ICU is an important goal, we believe that future communication studies should include at least one patient or family-centered outcome and all studies should include mortality.

\section{Data Limitations}

The data have important limitations. Many interventions were small and followed a pre-post design; their effects were attenuated when reattempted as larger trials or RCTs. Secular trends could account for some effects in pre-posts design. ICU culture has changed considerably with respect to end-of-life care in the past 15 years during which these studies have been conducted, and many authors commented on the changes they observed during the study period. All interventions were compared to usual care, and existing evidence does not provide for direct comparison of different forms of enhanced ICU communication. However, this research does establish an evidence base for the recommendations of critical care professional societies, which center around early, frequent, multidisciplinary communication with the goal of shared decision-making. ${ }^{7,48}$ 


\section{Study Limitations}

Our study may be limited by publication bias, as we did not systematically attempt to find research that has not been published. However, several of the reviewed studies did not show significant effects of their interventions, indicating willingness to publish negative studies in this field of research. Additionally, the search strategy itself may not have included all available studies; however, the same titles emerged repeatedly as we hand-searched reference lists. We did not individually communicate with the authors of included studies, so it is possible that studies did not report quality metrics that they did implement, which would lead to a falsely low impression of quality. Finally, the heterogeneity of the studies precluded meta-analysis or other summative analysis, and complicated transparent reporting.

\section{Conclusions}

We report a systematic review of interventions designed to improve provider-family communication in the Intensive Care Unit. Printed information can improve family comprehension and should be available in all ICUs. Regular, structured communication on the part of the usual care team or a specialized ethics or palliative care consult service can improve family distress, reduce use of intensive treatments, and decrease ICU LOS, without adversely affecting patient mortality. However, these data are insufficient to conclude that communications interventions result in meaningful total cost reductions. Although institutional factors will influence adoption of a particular communication strategy, physicians should provide leadership in prioritizing structured family conferences in their ICUs. A comprehensive research agenda should be developed to ensure that ICU communication strategies, and other palliative care interventions, provide evidence for effectiveness across a full range of standardized, validated patient and family-centered outcomes. 


\section{Acknowledgments}

Dr. Scheunemann had primary responsibility for the conception and design of the study, development of the search strategy, choice of data collection instruments, analysis of included studies, preparation and revision of the manuscript, and final approval of the version to be published. She is responsible for the integrity of the work as a whole, from inception to published article. Ms. McDevitt helped to refine the data collection instruments, performed data abstraction and analysis, assisted in drafting the manuscript and final approval of the version to be published. Dr. Carson provided assistance with data abstraction and analysis, revision for intellectual content, and gave final approval of the article to be published. Dr. Hanson guided the development of the data collection instruments and data analysis, performed abstraction and revision of the manuscript for intellectual content, and gave final approval of the article to be published. The Hartford Center of Excellence in Geriatric Medicine and Training supported this work but had no role in the conception, conduct, or reporting of the study. 


\section{References}

1. Curtis JR, Patrick DL, Shannon SE et al. The family conference as a focus to improve communication about end-of-life care in the intensive care unit: Opportunities for improvement. Crit Care Med. 2001;29 Suppl 2:N26-33.

2. Azoulay E, Pochard F, Kentish-Barnes N, et al. Risk of posttraumatic stress symptoms in family members of intensive care unit patients. Am J Respi Crit Care Med. 2005:171(9):987-94.

3. Prendergast TJ, Claessens MT, Luce JM. A national survey of end-of-life care for critically ill patients. Am J Respir Crit Care Med. 1998;158(4):1163-7.

4. van der Heide A, Deliens L, Faisst K, et al; on behalf of the EURELD Consortium. End-of-life decision-making in six European countries: descriptive study. The Lancet. 2003;362(9381):34550.

5. Miller PA, Forbes S, Boyle DK. End-of-life care in the intensive care unit: A challenge for nurses. Am J Crit Care. 2001;10(4):230-7.

6. Carlet J, Thijs L, Antonelli M et al. Challenges in end-of-life care in the ICU: Statement of the 5th international consensus conference in critical care: Brussels, Belgium, April 2003. Intensive Care Med. 2004;30(5):770-84.

7. Thompson BT, Cox PN, Antonelli M et al. Challenges in end-of-life care in the ICU: Statement of the 5th international consensus conference in critical care: Brussels, Belgium, April 2003: Executive summary. Crit Care Med. 2004;32(8):1781-4.

8. Azoulay E, Chevret S, Leleu G et al. Half the families of intensive care unit patients experience inadequate communication with physicians. Crit Care Med. 2000;28(8):3044-9.. 
9. Nelson JE. Identifying and overcoming the barriers to high-quality palliative care in the intensive care unit. Crit Care Med. 2006;34 Suppl 11:S324-31.

10. Truog RD, Cist AFM, Brackett SE et al. Recommendations for end-of-life care in the intensive care unit: The Ethics Committee of the Society of Critical Care Medicine. Crit Care Med. 2001;29(12):2332-48.

11. Connors AF, Dawson NV, Desbiens NA et al. Controlled trial to improve care for seriously ill hospitalized patients: The Study to Understand Prognoses and Preferences for Outcomes and Risks of Treatment (SUPPORT). JAMA. 1995;274(20):1591-8.

12. Boutron I, Moher D, Altman DG et al, for the CONSORT Group. Extending the CONSORT statement to randomized trials of nonpharmacologic treatment: Explanation and elaboration. Ann Intern Med. 2008;148(4):295-309

13. Campbell MK, Elbourne DR, Altman DG, CONSORT Group. CONSORT statement: Extension to cluster randomised trials. Br Med J. 2004;328(7441):702-8.

14. Des Jarlais DC, Lyles C, Crepaz N, the TREND Group. Improving the reporting quality of nonrandomized evaluations of behavioral and public health interventions: The TREND statement. Am J Public Health. 2004;94(3):361-6.

15. Liberati A, Altman DG, Tetzlaff $\mathrm{J}$ et al. The PRISMA statement for reporting systematic reviews and meta-analyses of studies that evaluate health care interventions: Explanation and elaboration. J Clin Epidemiol. 2009;62(10):e1-34.

16. Azoulay E, Pochard F, Chevret S et al. Impact of a family information leaflet on effectiveness of information provided to family members of intensive care unit patients: A 
multicenter, prospective, randomized, controlled trial. Am J Respir Crit Care Med. $2002 ; 165(4): 438-42$.

17. Lautrette A, Darmon M, Megarbane B et al. A communication strategy and brochure for relatives of patients dying in the ICU. N Engl J Med. 2007;356(5):469-78.

18. Medland JJ, Ferrans CE. Effectiveness of a structured communication program for family members of patients in an ICU. Am J Crit Care. 1998;7(1):24-9.

19. Curtis JR, Treece PD, Nielsen EL, et al. Integrating palliative and critical care: Evaluation of a quality improvement intervention. Am J Respir Crit Care Med. 2008:178(3):269-75.

20. Curtis JR, Nielsen EL, Treece PD, et al. Effect of a multi-faceted quality-improvement intervention on end-of-life care in the intensive care unit: A randomized trial. Unpublished.

21. McCormick AJ, Curtis JR, Stowell-Weiss P, Toms C, Engelberg R. Improving social work in intensive care unit palliative care: Results of a quality improvement intervention. $J$ Pall Med. 2010;13(3):297-304.

22. Schneiderman LJ, Gilmer T, Teetzel HD. Impact of ethics consultations in the intensive care setting: A randomized, controlled trial. Crit Care Med. 2000;28(12):3920-4

23. Schneiderman LJ, Gilmer T, Teetzel HD et al. Effect of ethics consultations on nonbeneficial life-sustaining treatments in the intensive care setting: A randomized controlled trial. JAMA. 2003;290(9):1166-72.

24. Dowdy MD, Robertson C, Bander JA. A study of proactive ethics consultation for critically and terminally ill patients with extended lengths of stay. Crit Care Med. 1998;26(2):252-9. 
25. Mosenthal AC, Murphy PA, Barker LK et al. Changing the culture around end-of-life care in the trauma intensive care unit. J Trauma. 2008;64(6):1587-93.

26. Norton SA, Hogan LA, Holloway RG et al. Proactive palliative care in the medical intensive care unit: Effects on length of stay for selected high-risk patients. Crit Care Med. $2007 ; 35(6): 1530-5$.

27. Campbell ML, Guzman JA. A proactive approach to improve end-of-life care in a medical intensive care unit for patients with terminal dementia. Crit Care Med. 2004;32(9):1839-43.

28. Campbell ML, Guzman JA. Impact of a proactive approach to improve end-of-life care in a medical ICU. Chest. 2003;123(1):266-71.

29. Kaufer M, Murphy P, Barker K et al. Family satisfaction following the death of a loved one in an inner city MICU. Am J Hosp Palliat Care. 2008 Aug-Sep;25(4):318-25.

30. Ahrens T, Yancey V, Kollef M. Improving family communications at the end of life: Implications for length of stay in the intensive care unit and resource use. Am J Crit Care. $2003 ; 12(4): 317-24$.

31. Shelton W, Moore CD, Socaris S, Gao J, Dowling J. The effect of a family support intervention on family satisfaction, length-of-stay, and cost of care in the intensive care unit. Crit Care Med. 2010;38:1315-20.

32. Burns JP, Mello MM, Studdert DM et al. Results of a clinical trial on care improvement for the critically ill. Crit Care Med. 2003;31(8):2107-17.

33. Lilly CM, De Meo DL, Sonna LA et al. An intensive communication intervention for the critically ill. Am J Med. 2000;109(6):469-75. 
34. Lilly CM, Sonna LA, Haley KJ et al. Intensive communication: Four-year follow-up from a clinical practice study. Crit Care Med. 2003;31 Suppl 5:S394-9.

35. Daly BJ, Douglas SL, O'Toole E, et al. Effectiveness trial of an intensive communication structure for families of long-stay ICU patients. Chest. 2010.

http://chestjournal.chestpubs.org/content/early/2010/06/23/chest.10-0292.long. Accessed Aug $14,2010$.

36. Steel A, Underwood C, Notley $\mathrm{C}$ et al. The impact of offering a relatives' clinic on the satisfaction of the next-of-kin of critical care patients-A prospective time-interrupted trial. Intensive Crit Care Nurs. 2008;24(2):122-9.

37. Kahn JM. Understanding economic outcomes in critical care. Curr Opin Crit Care. 2006;12(5):399-404.

38. Luce JM, Rubenfeld GD. Can heathl care costs be reduced by limiting intensive care at the end of life? Am J Respir Crit Care Med. 2002;165(6);750-4.

39. Selph RB, Shiang J, Engelberg R et al. Empathy and life support decisions in intensive care units. J Gen Intern Med. 2008;23(9):1311-7.

40. Curtis JR, Engelberg RA, Wenrich MD et al. Missed opportunities during family conferences about end-of-life care in the intensive care unit. Am J Respir Crit Care Med. 2005;171(8):844849.

41. McDonagh JR, Elliott TB, Engelberg RA et al. Family satisfaction with family conferences about end-of-life care in the intensive care unit: Increased proportion of family speech is associated with increased satisfaction. Crit Care Med. 2004;32(7):1484-8. 
42. Lee Char SJ, Evans LR, Malvar GL, White DB. A randomized trial of two methods to disclose prognosis to surrogate decision makers in ICUs. Am J Respir Crit Care Med. 2010. http://ajrccm.atsjournals.org/cgi/reprint/201002-0262OCv1. Accessed Aug. 14, 2010.

43. White DB, Braddock III CH, Bereknyei S, Curtis JR. Toward shared decision making at the end of life in intensive care units: Opportunities for improvement. Arch Intern Med. $2007 ; 167(5): 461-7$.

44. White DB, Malvar G, Karr J, Lo B, Curtis JR. Expanding the paradigm of the physician's role in surrogate decision-making: An empirically derived framework. Crit Care Med. 2010;38(3):74350.

45. Greco PJ, Eisenberg JM. Changing physicians' practices. N Engl J Med. 1993;329(17):1271-1274.

46. Curtis JR, Engelberg RA. Measuring success of interventions to improve the quality of endof-life care in the intensive care unit. Crit Care Med. 2006;34(11):S341.

47. Nelson JE, Mulkerin CM, Adams LL et al. Improving comfort and communication in the ICU: A practical new tool for palliative care performance measurement and feedback. Qual Saf Health Care. 2006;15(4):264-71

48. Davidson JE, Powers K, Hedayat KM, et al. Clinical practice guidelines for support of the family in the patient-centered intensive care unit: American college of critical care medicine task force 2004-2005. Crit Care Med. 2007;35(2):605-22. 


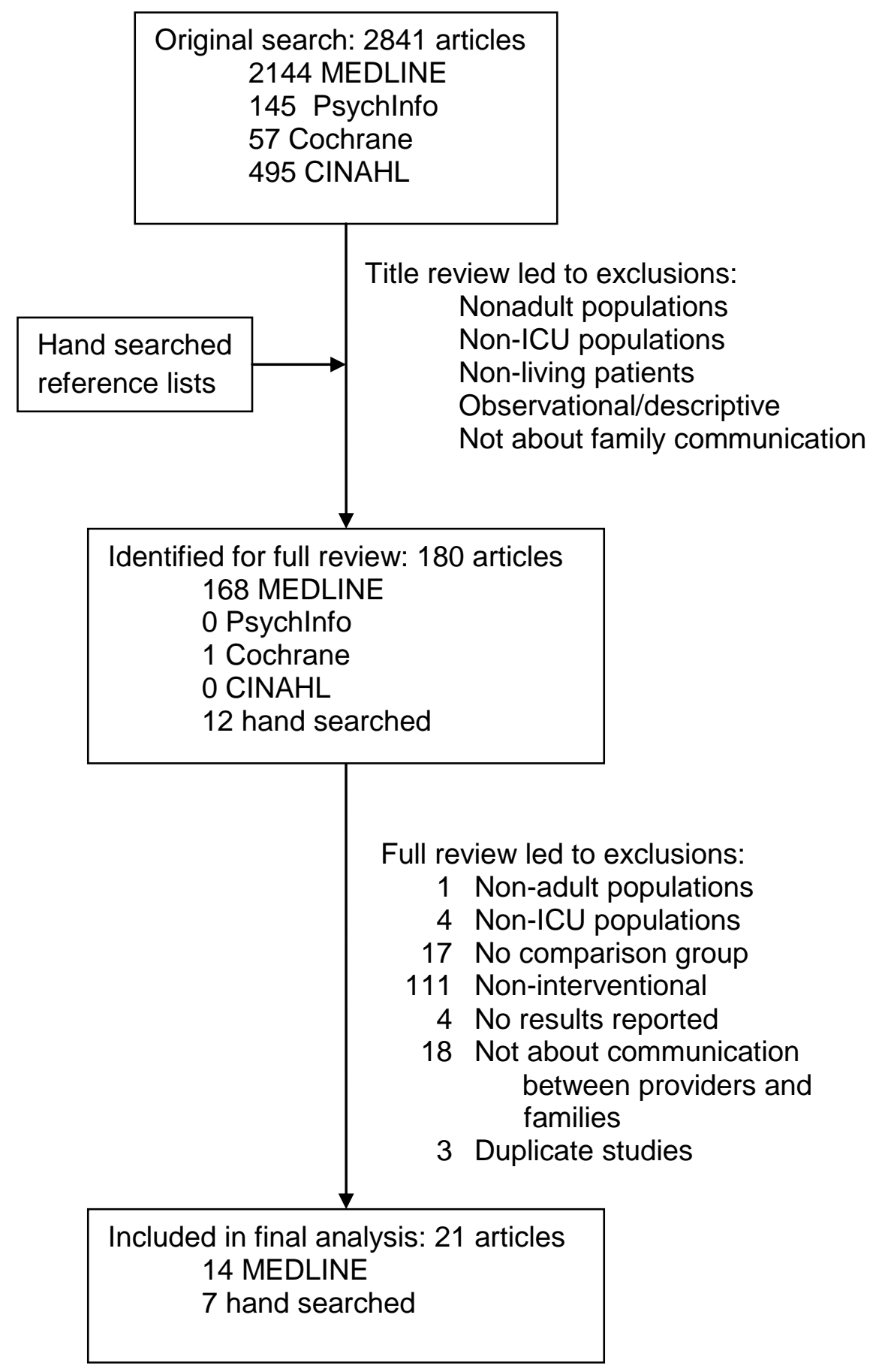

Figure 1. Flow diagram of article inclusion. 
Table 1. Quality Metrics

\begin{tabular}{||l|l|c|}
\hline \multicolumn{1}{||c|}{ Metric } & \multicolumn{2}{c|}{ Parameters } \\
\hline Type of controls & Randomized & $\begin{array}{c}\text { Number of Studies } \\
\text { (\%) }\end{array}$ \\
\hline Sample size & Power calculation present & $6 / 16(25 \%)$ \\
\hline Participant flow & Clear & $10 / 16(38 \%)$ \\
\hline Data quality & $\begin{array}{l}\text { Monitored data accuracy or } \\
\text { reliability }\end{array}$ & $2 / 12(17 \%)$ \\
\hline Primary outcome measures & Prespecified & $10 / 16(63 \%)$ \\
\hline Measurement tool & Externally validated & $7 / 10(70 \%)$ \\
\hline Adherence to intervention & $>70 \%$ & $8 / 15(53 \%)$ \\
\hline $\begin{array}{l}\text { Missing data for primary } \\
\text { outcome }\end{array}$ & $\begin{array}{l}<25 \% \\
\text { Study population restricted to } \\
\text { patients who died }\end{array}$ & $4 / 10(40 \%)$ \\
\hline Patient mortality & Nossible increase in mortality \\
& Not reported & 1 \\
\hline
\end{tabular}


Table 2. Measurement instruments for satisfaction, communication, and decision-making outcomes

\begin{tabular}{|c|c|c|c|c|c|c|}
\hline Validation & Instrument* & Study & Outcomes & Scale & Subscales (items) & Interpretation \\
\hline \multirow[t]{5}{*}{$\begin{array}{l}\text { Previously } \\
\text { validated }\end{array}$} & $\begin{array}{l}\text { Hospital Anxiety } \\
\text { and Depression } \\
\text { Scale }\end{array}$ & $\begin{array}{l}\text { Azoulay }^{16} \\
\text { Lautrette }^{17}\end{array}$ & $\begin{array}{l}\text { Emotional } \\
\text { distress }\end{array}$ & $\begin{array}{l}0 \text { (no distress) }-21 \\
\text { (severe distress) }\end{array}$ & $\begin{array}{l}\text { Anxiety ( } 7 \text { items) } \\
\text { Depression ( } 7 \text { items) }\end{array}$ & $\begin{array}{l}\text { 8-10 indeterminate } \\
\text { >=11 on individual } \\
\text { subscale anxiety or } \\
\text { depression }\end{array}$ \\
\hline & $\begin{array}{l}\text { Impact of Events } \\
\text { Scale }\end{array}$ & Lautrette $^{17}$ & PTSD symptoms & $\begin{array}{l}0 \text { (no PTSD symptoms) } \\
-75 \text { (severe PTSD } \\
\text { symptoms) }\end{array}$ & $\begin{array}{l}\text { Intrusion (7 items) } \\
\text { Avoidance (8items) }\end{array}$ & $\begin{array}{l}>30 \text { high likelihood of } \\
\text { significant distress }\end{array}$ \\
\hline & $\begin{array}{l}\text { Family } \\
\text { Satisfaction-ICU }\end{array}$ & $\begin{array}{l}\text { Curtis }^{20} \\
\text { McCormick }^{21}\end{array}$ & $\begin{array}{l}\text { Family } \\
\text { satisfaction }\end{array}$ & $\begin{array}{l}0 \text { (low satisfaction) - } \\
100 \text { (high satisfaction) }\end{array}$ & $\begin{array}{l}\text { Satisfaction with } \\
\text { care } \\
\text { Satisfaction with } \\
\text { decision-making }\end{array}$ & $\begin{array}{l}\text { Total median } 85.4 \text { (IQR } \\
79.2-93.8) \\
\text { Care subscale median } \\
88.5 \text { (IQR 75-96.4) } \\
\text { Decision subscale } \\
\text { median } 82.5 \text { (IQR 70- } \\
\text { 92.5) }\end{array}$ \\
\hline & $\begin{array}{l}\text { Family } \\
\text { Satisfaction with } \\
\text { Care } \\
\text { Questionnaire }\end{array}$ & Kaufer $^{29}$ & $\begin{array}{l}\text { Family } \\
\text { satisfaction }\end{array}$ & $\begin{array}{l}0 \text { (extreme } \\
\text { dissatisfaction) }-100 \\
\text { (extreme satisfaction) }\end{array}$ & $\begin{array}{l}\text { Care of family (5 } \\
\text { items) } \\
\text { Care of patient ( } 4 \\
\text { items) } \\
\text { Professional Care (6 } \\
\text { items) } \\
\text { ICU environment ( } 2 \\
\text { items) }\end{array}$ & $\begin{array}{l}\text { Items analyzed } \\
\text { separately }\end{array}$ \\
\hline & Activities and & Curtis $^{19}$ - & Family & 0 (no SW activities & None & Median 6 activities per \\
\hline
\end{tabular}




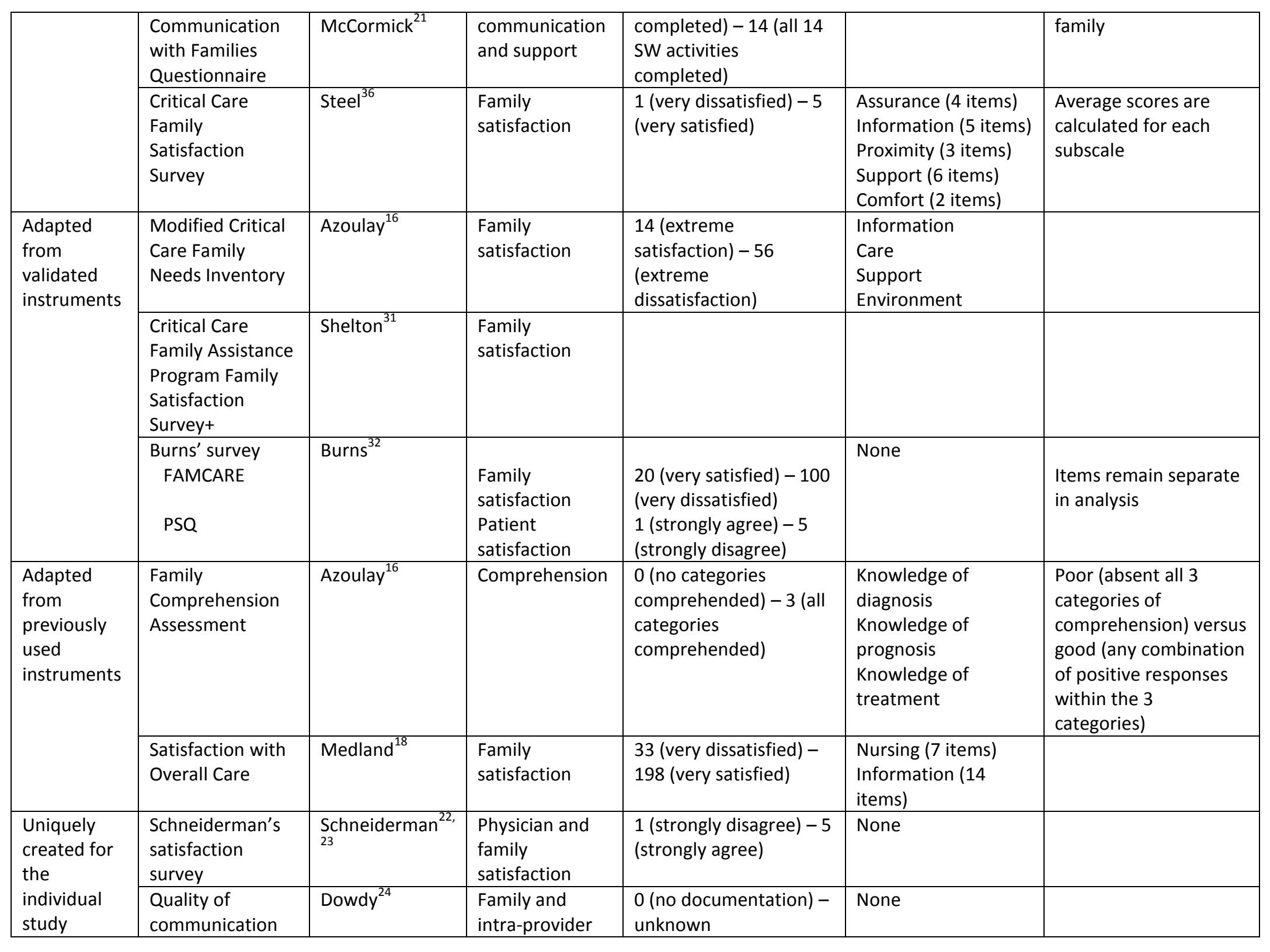




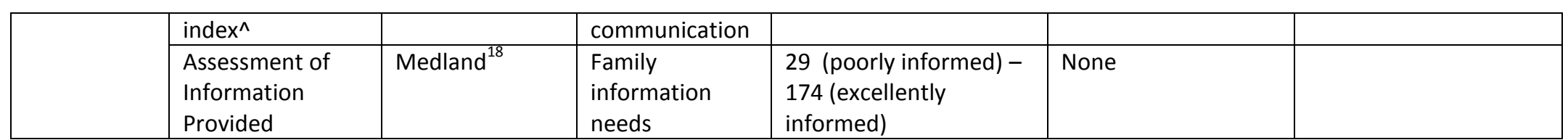

PSQ (Patient Satisfaction Questionnaire); PTSD (Post Traumatic Stress Disorder)

* References are to the

$\wedge 1$ point given for documentation of advance directives, DNR, orders to withhold or withdraw treatment, limits of care. 0.5 points given for consultation of pastoral care, social services, or pain management service

+ The Critical Care Family Assistance Program Family Satisfaction Survey was adapted from the Family Satisfaction with Care Questionnaire used by Kaufer et al. 
Table 3. Other methods used to measure communication and decision-making

\begin{tabular}{|c|c|c|}
\hline Study & Parameter & Outcomes \\
\hline Lautrette $^{17}$ & Communication & $\begin{array}{l}\text { Speaking time } \\
\text { Family reported guilt } \\
\text { Family reported successful expression of emotions } \\
\text { Family or ICU staff reported conflicts with each other }\end{array}$ \\
\hline Campbell $^{27,28}$ & Decision-making & Time to treatment-limiting decisions (DNR, CMO) \\
\hline Mosenthal $^{25}$ & $\begin{array}{l}\text { Decision-making } \\
\text { Communication }\end{array}$ & $\begin{array}{l}\text { Time to treatment-limiting decisions } \\
\text { Decisional conflict } \\
\text { Meeting goals of conference (discussion of goals of care, family understanding of information, } \\
\text { communication of patient preferences) }\end{array}$ \\
\hline Lilly $^{33}$ & Decision-making & $\begin{array}{l}\text { Days of provider team nonconsensus on disposition goals (transfer to floor, intended d/c home, } \\
\text { transfer to rehab or chronic care facility, or palliative care) } \\
\text { Days of family-provider nonconsensus }\end{array}$ \\
\hline Medland $^{18}$ & Communication & Incoming family telephone calls \\
\hline
\end{tabular}

CMO (Comfort Measures Only); DNR (Do Not Resuscitate); ICU (Intensive Care Unit) 
Table 4. Patient and family centered outcomes and resource utilization by study

\begin{tabular}{|c|c|c|c|c|}
\hline & \multicolumn{2}{|c|}{ Patient and family-centered outcomes } & \multicolumn{2}{|c|}{ Resource utilization } \\
\hline & Positive & Negative or neutral & Positive & Negative or Neutral \\
\hline Azoulay $^{16}$-printed information & $\begin{array}{l}\text { Family comprehension* } \\
(\mathrm{p}<0.0001)\end{array}$ & $\begin{array}{c}\text { Family depression and anxiety } \\
\text { or satisfaction }\end{array}$ & & \\
\hline $\begin{array}{l}\text { Lautrette }^{1 /} \text {-printed information + } \\
\text { conference }\end{array}$ & $\begin{array}{l}\text { Family PTSD*, depression, } \\
\text { and anxiety }(P<0.02)\end{array}$ & & $\begin{array}{l}\text { Decreased nonbeneficial } \\
\text { treatments }(p<0.04)\end{array}$ & ICU LOS+ \\
\hline $\begin{array}{l}\text { Curtis }^{20}, \text { Curtis }^{19} \text { and } \\
\text { McCormick }^{21} \text {-palliative care QI }\end{array}$ & & $\begin{array}{l}\text { Family and nurse-rated patient } \\
\text { quality of death and dying } \\
\text { (communication and palliation) }\end{array}$ & & \\
\hline $\begin{array}{l}\text { Schneiderman }^{22} \text { and } \\
\text { Schneiderman }^{23} \text {-ethics consult }\end{array}$ & & Family satisfaction\# & $\begin{array}{l}\text { Decreased nonbeneficial } \\
\text { treatments* }(p \leq 0.05) \\
\text { ICU LOS* }(p<0.03)\end{array}$ & \\
\hline Dowdy $^{24}$-ethics consult & $\begin{array}{l}\text { Improved communication } \\
\text { and decision-making } \\
(p<0.05)\end{array}$ & Increased mortality $(p<0.05)$ & Decreased LOS $(p<0.05)$ & \\
\hline Kaufer $^{29}$-palliative care consult & $\begin{array}{c}\text { Improved family } \\
\text { satisfaction* }(p<0.05)\end{array}$ & & & \\
\hline $\begin{array}{l}\text { Mosenthal }{ }^{25} \text {-palliative care } \\
\text { consult }\end{array}$ & $\begin{array}{l}\text { Improved communication } \\
\text { and decision-making }\end{array}$ & & $\begin{array}{l}\text { Decreased ICU and } \\
\text { hospital LOS for patients } \\
\text { who died }\end{array}$ & \\
\hline Norton $^{26}$-palliative care consult & & & $\begin{array}{c}\text { Decreased ICU } \\
\operatorname{LOS}^{*}(p=0.0001)\end{array}$ & Other LOS unchanged* \\
\hline $\begin{array}{l}\text { Campbell }^{21} \text { and Campbell } \\
\text { palliative care consult }\end{array}$ & $\begin{array}{l}\text { Improved decision-making } \\
\qquad(\mathrm{p}<0.05)\end{array}$ & & $\begin{array}{l}\text { Decreased LOS dementia } \\
\text { and } \mathrm{GCl}(\mathrm{p}<0.05)\end{array}$ & \\
\hline Burns $^{32}$ - social work conference & $\begin{array}{l}\text { Improved decision-making } \\
\qquad(\mathrm{p}<0.01)\end{array}$ & Family satisfaction* & & LOS \\
\hline Ahrens $^{30}-\mathrm{MD}+\mathrm{APN}$ conference & & & $\begin{array}{c}\text { Decreased LOS }(p<0.03) \\
\text { Decreased hospital charges } \\
(p<0.01)\end{array}$ & \\
\hline Shelton $^{31}$-APN conference & $\begin{array}{l}\text { Some family satisfaction } \\
\text { with communication }\end{array}$ & Communication parameters & & LOS, costs \\
\hline Lilly $^{33,34}$-conference & $\begin{array}{l}\text { Improved decision-making } \\
\qquad(p<0.01) \\
\text { Decreased mortality }\end{array}$ & & Decreased LOS $(p=0.01)$ & \\
\hline
\end{tabular}




\begin{tabular}{|c|c|c|c|c|}
\hline & $(p<0.001)$ & & & \\
\hline Daly ${ }^{35}$-conference & & $\begin{array}{l}\text { No change in family } \\
\text { satisfaction* }\end{array}$ & & \\
\hline $\begin{array}{l}\text { Steel }^{36} \text { —family initiated } \\
\text { conference }\end{array}$ & & Family satisfaction* & & \\
\hline Medland $^{18}$-telephone intervention & & $\begin{array}{c}\text { Family satisfaction or } \\
\text { communication }\end{array}$ & & \\
\hline \multirow[t]{2}{*}{ Summary } & $\begin{array}{c}3 \text { Communication } \\
5 \text { Decision-making } \\
1 \text { Family distress } \\
0 \text { Palliation } \\
2 \text { Satisfaction }\end{array}$ & $\begin{array}{c}3 \text { Communication } \\
0 \text { Decision-making } \\
1 \text { Family distress } \\
1 \text { Palliation } \\
6 \text { Satisfaction }\end{array}$ & $\begin{array}{c}2 \text { Non-beneficial treatments } \\
1 \text { Hospital charges } \\
7 \text { LOS }\end{array}$ & $\begin{array}{l}1 \text { Costs } \\
4 \text { LOS }\end{array}$ \\
\hline & $\begin{array}{r}\text { Primary outc } \\
1 \text { of } \\
0 \text { of } \\
1 \text { of } \\
1\end{array}$ & $\begin{array}{l}\text { ing intervention: } \\
\text { hication } \\
\text {-making } \\
\text { listress } \\
\text { tion } \\
\text { action }\end{array}$ & \multicolumn{2}{|c|}{$\begin{array}{c}\text { Primary outcomes favoring intervention: } \\
1 \text { of } 1 \text { Non-beneficial treatments } \\
2 \text { of } 3 \text { LOS }\end{array}$} \\
\hline
\end{tabular}

* Primary outcomes

\# No comparison group

+ Patient population defined as likely to die within a few days of enrollment

APN (Advance Practice Nurse); LOS (Length of Stay); PTSD (Post-traumatic stress disorder); QI (Quality Improvement) 
Table 5. Study quality characteristics.

\begin{tabular}{|c|c|c|c|c|c|c|c|c|c|}
\hline Intervention & Article & $\begin{array}{l}\text { Study } \\
\text { design+ }\end{array}$ & $\begin{array}{c}\text { Intervention } \\
/ \\
\text { control }\end{array}$ & $\begin{array}{l}\text { Participant } \\
\text { flow clear^ }\end{array}$ & Providers & $\begin{array}{l}\text { Adherence } \\
\text { to } \\
\text { intervention } \\
\wedge\end{array}$ & Missing data^ & $\begin{array}{l}\text { Monitored } \\
\text { data for } \\
\text { accuracy/ } \\
\text { reliability }\end{array}$ & $\begin{array}{c}\text { Prespecified } \\
\text { primary } \\
\text { outcomes^ }^{\wedge}\end{array}$ \\
\hline $\begin{array}{c}\text { Printed } \\
\text { information }\end{array}$ & Azoulay ${ }^{16}$ & $\begin{array}{c}\text { RCT } \\
\text { (blinded) }\end{array}$ & $87 / 88^{*}$ & Yes & ICU personnel & $100 \%$ & $0 \%$ & NA & Yes \\
\hline $\begin{array}{l}\text { Conference + } \\
\text { printed } \\
\text { information }\end{array}$ & Lautrette $^{17}$ & RCT & $63 / 63^{*}$ & Yes & ICU personnel & $\geq 70 \%$ & Unknown & No & Yes \\
\hline $\begin{array}{c}\text { Conference + } \\
\text { telephone } \\
\text { updates + } \\
\text { printed } \\
\text { information }\end{array}$ & Medland $^{18}$ & Pre-post & $15 / 15$ & Yes & ICU personnel & Unknown & $<10 \%$ & NA & No \\
\hline \multirow{2}{*}{$\begin{array}{l}\text { Palliative Care } \\
\text { Quality } \\
\text { Improvement }\end{array}$} & $\begin{array}{l}\text { Curtis }^{19} \text { and } \\
\text { McCormick }^{21}\end{array}$ & Pre-post & $337 / 253$ & No & ICU personnel & QI & $\begin{array}{l}>25 \% \text { missing } \\
\text { survey data }\end{array}$ & No & Yes \\
\hline & Curtis $^{20}$ & Cluster RCT & 669/570* & No & ICU personnel & QI & $\begin{array}{c}<10 \% \text { Quantitative } \\
>25 \% \text { missing } \\
\text { survey data }\end{array}$ & Yes & Yes \\
\hline \multirow{2}{*}{$\begin{array}{c}\text { Ethics } \\
\text { consultation }\end{array}$} & $\begin{array}{l}\text { Schneiderman } \\
{ }^{21} \text { single site }^{22}\end{array}$ & RCT & $35 / 35^{*}$ & Yes & $\begin{array}{c}\text { Additional } \\
\text { personnel-ethics } \\
\text { consult }\end{array}$ & $\geq 70 \%$ & $\begin{array}{c}<10 \% \text { Quantitative } \\
>25 \% \text { missing } \\
\text { interview data }\end{array}$ & No & Yes \\
\hline & $\begin{array}{c}\text { Schneiderman } \\
\text { multisite }^{23}\end{array}$ & $\begin{array}{c}\text { RCT } \\
\text { (blinded) }\end{array}$ & $278 / 273^{*}$ & Yes & $\begin{array}{c}\text { Additional } \\
\text { personnel-ethics } \\
\text { consult }\end{array}$ & $\geq 70 \%$ & $\begin{array}{c}<10 \% \text { Quantitative } \\
\text { Unknown missing } \\
\text { data for provider } \\
\text { interviews }\end{array}$ & No & Yes \\
\hline $\begin{array}{c}\text { Ethics } \\
\text { consultation }\end{array}$ & Dowdy $^{24}$ & $\begin{array}{l}\text { Non- } \\
\text { randomize }\end{array}$ & $31 / 68$ & Yes & $\begin{array}{c}\text { Additional } \\
\text { personnel-ethics }\end{array}$ & $100 \%$ & Unknown & No & Yes \\
\hline
\end{tabular}




\begin{tabular}{|c|c|c|c|c|c|c|c|c|c|}
\hline & & $\mathrm{d}$ controls & & & consult & & & & \\
\hline $\begin{array}{c}\text { Palliative care } \\
\text { team }\end{array}$ & Mosenthal $^{25}$ & Pre-post & $367 / 286$ & Yes & $\begin{array}{c}\text { Additional } \\
\text { personnel- } \\
\text { palliative care } \\
\text { team }\end{array}$ & $>50 \%$ & $<10 \%$ & No & No \\
\hline $\begin{array}{l}\text { Palliative care } \\
\text { consultation }\end{array}$ & Norton $^{26}$ & Pre-post & $126 / 65$ & Yes & $\begin{array}{c}\text { Additional } \\
\text { personnel- } \\
\text { palliative care } \\
\text { consult }\end{array}$ & $100 \%$ & $<10 \%$ & No & Yes \\
\hline \multirow{2}{*}{$\begin{array}{l}\text { Palliative care } \\
\text { consultation }\end{array}$} & $\begin{array}{c}\text { Campbell } \\
\text { dementia }^{27}\end{array}$ & $\begin{array}{c}\text { Historical } \\
\text { controls }\end{array}$ & $26 / 26$ & No & $\begin{array}{c}\text { Additional } \\
\text { personnel- } \\
\text { palliative care } \\
\text { consult }\end{array}$ & Unknown & None & No & No \\
\hline & $\begin{array}{c}\text { Campbell } \\
{\text { GCl} / M^{2}{ }^{28}}^{28}\end{array}$ & $\begin{array}{l}\text { Historical } \\
\text { controls }\end{array}$ & $\begin{array}{c}20 / 18 \mathrm{GCl} \\
22 / 21 \mathrm{MOSF}\end{array}$ & No & $\begin{array}{c}\text { Additional } \\
\text { personnel- } \\
\text { palliative care } \\
\text { consult }\end{array}$ & Unknown & None & No & No \\
\hline $\begin{array}{l}\text { Palliative care } \\
\text { consultation }\end{array}$ & Kaufer $^{29}$ & Pre-post & $45 / 43$ & Yes & $\begin{array}{c}\text { Additional } \\
\text { personnel-family } \\
\text { support team, } \\
\text { palliative care } \\
\text { consult }\end{array}$ & Unknown & $\begin{array}{c}>25 \% \text { missing } \\
\text { survey data }\end{array}$ & NA & Yes \\
\hline $\begin{array}{c}\text { APN } \\
\text { conference }\end{array}$ & Shelton $^{31}$ & Pre-post & $187 / 190$ & No & $\begin{array}{c}\text { Additional } \\
\text { personnel- } \\
\text { advance practice } \\
\text { nurse }\end{array}$ & Unknown & $\begin{array}{l}\text { Chart review } \\
\text { unknown } \\
>25 \% \text { missing } \\
\text { survey data }\end{array}$ & No & No \\
\hline $\begin{array}{l}\mathrm{MD}+\mathrm{APN} \\
\text { conference }\end{array}$ & Ahrens $^{30}$ & $\begin{array}{l}\text { Non- } \\
\text { randomize } \\
\text { d controls }\end{array}$ & $43 / 108$ & No & $\begin{array}{c}\text { Additional } \\
\text { personnel- } \\
\text { advance practice }\end{array}$ & Unknown & Unknown & No & No \\
\hline
\end{tabular}




\begin{tabular}{|c|c|c|c|c|c|c|c|c|c|}
\hline & & & & & nurse & & & & \\
\hline $\begin{array}{l}\text { Social work } \\
\text { conference }\end{array}$ & Burns $^{32}$ & $\begin{array}{l}\text { Non- } \\
\text { randomize } \\
\text { d controls }\end{array}$ & $493 / 256$ & No & ICU personnel & $<50 \%$ & $\begin{array}{c}\text { Chart review } \\
\text { unknown } \\
>25 \% \text { missing } \\
\text { satisfaction data }\end{array}$ & No & Yes \\
\hline \multirow{2}{*}{ Conference } & Lilly pilot ${ }^{33}$ & Pre-post & $396 / 134$ & No & ICU personnel & $\geq 70 \%$ & Unknown & No & No \\
\hline & Lilly $\mathrm{f} / \mathrm{u}^{34}$ & Pre-post & $2361 / 134$ & No & ICU personnel & Unknown & Unknown & No & No \\
\hline Conference & Daly ${ }^{35}$ & Pre-post & $354 / 135^{*}$ & Yes & ICU personnel & $\geq 70 \%$ & Unknown & Yes & Yes \\
\hline Family clinic & Steel $^{36}$ & $\begin{array}{c}\text { Time- } \\
\text { interrupted } \\
\text { (A-B-A) }\end{array}$ & $151 / 170^{*}$ & Yes & ICU personnel & $100 \%$ & $\begin{array}{c}>25 \% \text { missing } \\
\text { satisfaction data }\end{array}$ & NA & Yes \\
\hline
\end{tabular}

+ Pre-post studies are those with prospective usual care cohort (pre) followed by a prospective intervention cohort (post). Non-randomized controls include studies with provider-based assignment to concurrently enrolled intervention and control groups.

* Power calculations performed based on pre-specified primary outcomes

$\wedge$ In reporting statistics in Table 1, we did not "double count" multiple trials testing the same intervention

APN (advance practice nurse); CGI (Global Cerebral Ischemia); DNR (Do Not Resuscitate); ICU (Intensive Care Unit); MOSF (Multi-Organ System Failure); N/A

(Not Applicable); PTSD (Post-Traumatic Stress Disorder); QI (Quality Improvement-intervention dynamic and provider-focused); RCT (Randomized Controlled Trial) 
Appendices to Systematic Review: Controlled Trials of Interventions to Improve Communication in Intensive Care

Leslie P. Scheunemann, MD ${ }^{1}$

All work on this manuscript was performed at the University of North Carolina at Chapel Hill.

${ }^{1}$ Division of Geriatric Medicine and Center for Aging and Health, University of North Carolina Hospitals, Chapel Hill, NC 
It is much more important to know what sort of a patient has a disease than what sort of a disease a patient has. -Sir William Osler

\section{Appendix A: Introduction}

Medicine has aggressively pushed its frontiers in the past one hundred years. However, as it has done so, it has inadvertently introduced new diseases and new ways of suffering. For example, the advent of transfusion medicine extended the lives of countless individuals suffering hemorrhages, but massive transfusion also created transfusion-related acute lung injury. ${ }^{1}$ Although antibiotics revolutionized the treatment of pneumonia and then other infections, their wide-spread use has permitted antibiotic resistant bacteria to evolve and facilitated frequent nosocomial infections. ${ }^{2}$

One of the sites of dramatic innovation has been the intensive care unit (ICU). The list of powerful technologies in common use in the ICU is impressive: mechanical ventilators, central catheters, antibiotics, continuous dialysis, and arterial catheters are only a few. Although they save lives in many cases, they also represent a frontier of medicine. At the frontier, outcomes of care are unpredictable. ${ }^{3}$ ICU patients can undergo remarkable recoveries; survive with physical, cognitive, or emotional impairments; or die. ${ }^{4-6}$ This wide range of outcomes makes it challenging to assign a priori value to medical care.

In fact, the history of intensive care medicine is marked by patient families and providers struggling to understand the value of this care and its ethical implications. In 1976, Karen Ann Quinlan's family sued hospital officials for the right to remove her from mechanical ventilation. ${ }^{7}$ This case led to the establishment of ethics committees in many hospitals, ${ }^{8}$ an Institute of Medicine report to define an overarching agenda, ${ }^{9}$ and new areas of research. Throughout this time, autonomy became a more important principle of medical ethics, and the limitations of 
medical technology to meaningfully sustain life in some cases became clear. As this occurred, decisions to withhold or withdraw care became more frequent. Now, most of the half-million deaths each year that occur in or soon after an ICU stay are preceded by a decision to forgo life-sustaining treatment. ${ }^{10,11}$

During these decisions, medical providers and surrogate decision-makers evaluate the patient's clinical condition, prognosis for meaningful recovery of cognitive and physical function, and the burdens of treatment. When surrogates come to believe that the burdens of continued treatment outweigh the value the patient would place on the potential benefits, they make a shared decision with the medical team not to initiate more invasive treatments, or potentially to stop treatments that have not produced desired benefits. At such times, the goals of care become palliative.

Although this process has a simple formulation, it is cognitively and emotionally challenging for families and demands a special skill set of medical providers. And because so many technological changes have occurred recently, achieving appropriate social norms for what is possible and ethical norms for what is right has been difficult. ${ }^{12}$ For example, many people grossly overestimate the effectiveness of cardiopulmonary resuscitation. ${ }^{13}$. Other medical technologies are probably similarly misunderstood, so families likely have inappropriate expectations of the outcomes of medical care. And the shift in medical ethics from paternalism to autonomy has not only challenged medical providers, but also left patients and families uncertain about the relative roles of biomedicine and their values in treatment decisions. ${ }^{14}$

Although social and ethical norms of care are important to guide expectations and actions in such uncertainty, the norms will continue to change with technology and culture. However, processes for helping patients, their families, and medical providers to share information and 
negotiate about appropriate care can provide stability and support for ethical practice even as social and ethical norms change. Evidence-based, standardized processes will help people to address the challenges that the frontiers of medicine will always present, even as they advance.

\section{ICU patients' multiple sources of vulnerability}

Developing evidence-based processes for ICU communication also will begin to address the vulnerability of the ICU patient population. This vulnerability has two parts: (1) without adequate representation, they are subjected to invasive treatments without active choice and (2) they are susceptible to harm, loss, and indignity. ${ }^{15}$ Although the invasive treatments may be life saving, they can be provided in situations that are at least constraining and may even sometimes reach the level of coercion. Constraints occur when patients or their chosen surrogates do not perceive any choice, or feel powerless to alter the course of medical treatments. Coercion may occur if patients are sedated to prevent willful self-extubations or if the threat of death as a consequence of discontinuing treatments paralyzes decision-making.

The potential for constraining or coercive situations or for harm or indignity derives from patientrelated, surrogate-related, and bioethical factors as well as the challenges of advocating for a voiceless, fragmented population. Patient-related sources of vulnerability include the lifethreatening illness itself, communication impairments resulting from delirium or sedation, and the tight technological control of patients' physiologic parameters which alters their mobility and sensoria. ${ }^{16-18}$ ICU patients' symptom burdens are high, with more than half of survivors recalling moderate to severe pain and panic. ${ }^{19}$ Finally, most have not communicated clearly applicable treatment preferences. ${ }^{20-23}$

Beyond this lack of advance directives, surrogate decision-makers are generally unprepared for their role. They have high rates of anxiety, post-traumatic stress, and depressive disorders. ${ }^{24-26}$ 
Additionally, they face cognitive challenges including poor understanding of diagnosis, prognosis, and treatment options as well as a sense of inadequate communication with physicians. $^{27}$ These factors impede decision-making for ICU patients and also likely constitute independent vulnerabilities for the surrogates themselves. Whether they also contribute to decisional regret, lack of preparation for caregiving roles, or dysfunctional grieving is unknown.

Surrogate decision-making for ICU patients also involves special bioethical considerations. Bioethics recognizes three standards of surrogate decision-making. ${ }^{28}$ Advance directives are considered statements of treatment preferences. They represent a form of autonomous expression and therefore take precedence over the others. However, because most patients have not left clear and applicable directives, ${ }^{21,22}$ surrogates most frequently are asked to make substituted judgments. Substituted judgments are the best estimate of what the patient would have chosen, based on prior expressions of value. The last standard of surrogate decisionmaking is best-interest judgments, in which a broader conceptualization of what serves the patient's well-being guides treatment decisions. Substituted judgments take precedence over best-interest judgments. Because of ICU patients' incapacity, data describing surrogates' ability to make accurate substituted judgments are unavailable. However, surrogates of patients who are not critically ill are frequently unable to correctly identify what the patient would choose. ${ }^{29}$ Ultimately, provision of patient-centered care requires more accurate methods for making substituted judgments.

Finally, organizing advocacy efforts for ICU patients is difficult. No single disease unifies them. Their illnesses are unpredictable, acute, and of highly variable duration. They are geographically isolated in ICUs, and survivors live in long-term acute care hospitals, skilled nursing facilities, or at home. They are unlikely ever to have contact with each other. Family members of those who die grieve and then must move on with their lives; many family members 
of those who survive shoulder large caregiving burdens. There is no obvious place for advocates to voice their concerns, or group to whom they should speak. The likelihood of any group with a cohesive message forming and speaking effectively to those with the power to change practice is low.

\section{Providers' responses to perceived poor treatment decisions for ICU patients}

In fact, much recent advocacy seems to originate within the medical profession as it begins to recognize the broader role for palliative care for many patients. It begins at the bedside with dedicated clinicians attempting to address the challenges of uncertainty, possibility, suffering, and hope for individual patients and their families. ${ }^{30}$ The bedside role has also led to treatment recommendations, guidelines, and teaching tools, ${ }^{12}$ research on how to improve decisionmaking, and work to start a public dialogue about the role for intensive care within medical care. ${ }^{31,32}$ Hopefully, these efforts will help citizens to understand the limitations of medical technology and the role of value-based decision-making, spur them to join a dialogue with the medical profession about how to provide good care at the end of life, and start developing skills for participation in shared decision-making.

These advocacy efforts by clinicians evidence the enormous conflicts they face in providing care that is of questionable value to patients, is associated with severe suffering, and still often ends in mortality. Rates of burnout among ICU clinicians are high. ${ }^{33}$ The nursing literature is rife with concern and even moral distress about the roles they play in sustaining some patients' lives. ${ }^{34-36}$ Advocacy is one responsible reaction to this situation. Research is another. In fact, research into improved communication with surrogates likely represents not only a means to improve care for patients but also to reduce provider burdens by allowing them to confirm the value patients and families place on care. 


\section{Escalating resource use in the ICU}

Although ICU patients as a group often have low visibility outside the healthcare system, the costs of their care make them highly visible to administrators, policy-makers, and providers: ICU care consumes approximately $1-2 \%$ of the Gross Domestic Product. ${ }^{37}$ Its contribution to the Center for Medicare and Medicaid Services (CMS) budget has not recently been investigated, but over $25 \%$ of the CMS budget is spent on care delivered in the last year of life. ${ }^{38}$ As ICU care represents a substantial portion of this, and some patients survive their ICU stays, CMS expenditures on ICU care are also expected to be large. The concern that many patients might not choose to receive the care they do leads many to question whether ICU care is an effective use of healthcare resources. The abundance of cost-effectiveness research in ICUs speaks to the urgency of these concerns. ${ }^{39-41}$ As the outcomes investigated in our systematic review demonstrate, ${ }^{42-51}$ some have hoped ICU communication would increase efficient use of ICU resources by decreasing intensity and length of unwanted treatment.

\section{The SUPPORT Study and Beyond}

The combination of large numbers of patients with high vulnerability and suffering, poor health outcomes for their surrogates, ambiguous ethical value of their care, stress their care places on healthcare providers, and strains high-cost ICU care places on the healthcare system makes the care of ICU patients an important public health problem. In the 1990s, the problem had become large enough that investigators at five institutions across the United States conducted the landmark Study to Understand Prognosis and Preferences for Outcomes and Risks of Treatment (SUPPORT). ${ }^{52}$ It cluster-randomized participating specialties and enrolled over 5,000 hospitalized patients at high risk of death. Intervention patients had detailed prognostic information documented in the charts and intensive nurse-facilitated communication with patients and families. Its failure to improve physicians' knowledge of patient preferences for end-of-life care, patient symptom burdens, or fulfillment of patient preferences was 
disappointing for the whole community of patients and providers anxious to address the growing burdens of care for those with life-threatening illness.

It also challenged those trying to improve this care to develop interventions that would be more effective. The SUPPORT intervention had been intensive in its use of nursing time and expertise and it had been well-designed. Intuitively, it seemed like it should work. How were clinicians and researchers to invest their time, and funding agencies to invest money, in other interventions with similar intuitive appeal without clearer likelihood success?

But dedicated individuals did continue to work on this problem. Observational studies improved the characterization of surrogate-physician communication difficulties. ${ }^{53-55}$ Consensus statements and quality improvement work by influential groups helped to focus interest and suggest directions. ${ }^{56-58}$ Interventions began with locally and at relatively low-cost, largely with physicians in the lead. Pre-post studies allowed researchers to collect data at their institutions and locally implement interventions without the administrative burdens of randomization. Several began to demonstrate some improvements in communication or decreases in patient lengths of stay. Most focused on family conferences, which increasingly became standard concepts in communicating with surrogates in ICUs. ${ }^{56}$

The family conference generally involves communication about diagnosis, prognosis, and treatment options. Ideally, it is held within 48 to 72 hours of admission for patients with poor or highly uncertain prognoses. Participants include at least a physician and the family member with decision-making authority, but multiple family members, nurses, social workers, chaplains, and other staff members sometimes attend. 
After fifteen years of interventions since SUPPORT, taking stock of family communications interventions in the ICU will identify the most effective interventions, and the most promising outcomes evaluated to date. It will also allow side-de-by-side comparison of ineffective interventions to discern their common characteristics so that future research can avoid their pitfalls. Finally, it will suggest important gaps in the evidence for future research. Because ICU communication represents an opportunity to improve patient- and family-centered outcomes while also reducing utilization of resources, these categories of outcomes will be the focus of our study. 


\section{Appendix B: Methods}

Search strategies

MEDLINE

The formal algorithm for searching MEDLINE was ("intensive care unit"[All Fields] OR "intensive care units"[All Fields] OR ICU[All Fields] OR "critical care"[All Fields] OR "critical care"[MH]) AND (("communication"[MeSH Terms] OR "communication"[All Fields]) OR communicate[All Fields] OR "decision making"[All Fields] OR "decision making"[MH]) AND ("family"[All Fields] OR "families"[All Fields] OR ("family"[MeSH Terms] OR "family"[All Fields] OR son[TW] OR husband[TW] OR daughter[TW] OR wife[TW] OR child[TW] OR parent[TW] OR spouse[TW])). We included English-language articles published after SUPPORT through July 19, 2010.

\section{PsychInfo, Cochrane Review, and CINAHL}

We searched the PsychInfo, Cochrane Review, and CINAHL databases using the search terms (adult AND (intensive care OR critical care OR ICU) AND (communication OR decision making OR meeting OR communicate) AND (family OR families OR son OR daughter OR parent OR spouse OR husband OR wife OR significant other OR partner) as keywords. Again, we included English-language articles published after SUPPORT through July 19, 2010.

\section{Hand-searched articles}

We hand-searched reference lists of included articles for additional titles for review. Additionally, we learned of ongoing studies through attending national meetings, and obtained researchers' permission to review their articles pending publication. Unfortunately, we were unable to apply any systematic method for identifying unpublished literature, but the method used represented an attempt to capture all current relevant studies. 


\section{Evaluating study quality}

We used two data abstraction methods to evaluate study quality. One was a quality abstraction tool adapted from the CONSORT criteria $^{59}$ (Appendix B Table 1). The other was a critical appraisal tool developed by professors at the Gillings School of Global Public Health at the University of North Carolina at Chapel Hill (Appendix B Table 2).

The main purposes of the CONSORT criteria are to increase the transparency of reporting of randomized control trials (RCT) and to standardize reporting to facilitate evaluation by readers. Therefore, our checklist is a binary characterization of the presence or absence of information important to evaluating study quality. Reported information still requires interpretation; absent information raises concerns about study quality but may represent a simple omission rather than a methodological flaw.

On the other hand, the critical appraisal tool probes specifically for judgments about the potential for selection, measurement, and confounding bias and an overall assessment of the internal and external validity of the study. Thus, it provides a deeper synthesis of the study design and conduct. However, it does rely on a more subjective evaluation of studies than the quality abstraction tool. Therefore, the two complement each other.

Having two reviewers independently complete these tools for each study diminished the potential for measurement bias within our own work. Agreement among the reviewers was greater than $95 \%$ for those parameters with binary answers across all studies. Judgments of internal validity were also consistent. 
Organizing the studies

Because our study aimed to synthesize the whole field of interventions, our choices of inclusion and exclusion criteria ensured we did not omit any relevant trials. However, they also led us to identify a heterogeneous group of complex interventions. This heterogeneity precluded metaanalysis and made presentation of the findings difficult. Organizing the studies in a transparent way was necessary to facilitate assessment of differences in methodology and quality.

Although our study question suggested organization by patient- or family-centered outcomes and resource utilization outcomes, further organization was needed. Therefore, we reported RCTs first, to highlight their superior methodology. After that, we reported studies grouped by the major component of their interventions: ethics consultation, palliative care consultation, interventions led by other specialized personnel, and interventions led by usual ICU personnel. 
Appendix B Table 1. Quality abstraction tool adapted from the CONSORT criteria ${ }^{59}$

\begin{tabular}{|c|c|c|c|}
\hline Study citation: & & & \\
\hline \multicolumn{4}{|l|}{ Background } \\
\hline & Description of experimental treatment & (write out) & \\
\hline & $\begin{array}{l}\text { Baseline clinical and demographic } \\
\text { characteristics of each group provided? }\end{array}$ & & \\
\hline & & For patients? & \\
\hline & & For family members? & \\
\hline & $\begin{array}{l}\text { Description of care providers (case volume, } \\
\text { qualifications, expertise, etc.) provided? }\end{array}$ & Case volume, qualifications, expertise, etc. & \\
\hline \multicolumn{4}{|l|}{ Participants } \\
\hline & Allocation & & \\
\hline & & Randomized & \\
\hline & & Concurrent controls & \\
\hline & & Historical controls & \\
\hline & & Pre-post design & \\
\hline & & Other control (specify)? & \\
\hline & & $\begin{array}{l}\text { Any indication of how providers were } \\
\text { allocated to group? }\end{array}$ & \\
\hline & Care providers & & \\
\hline & & $\begin{array}{l}\text { Numbers of providers involved specified (if } \\
\text { yes, number)? }\end{array}$ & \\
\hline & & & $\begin{array}{l}\text { Experimental } \\
\text { group }\end{array}$ \\
\hline & & & Control group \\
\hline & & Tertiary care university hospital & \\
\hline & & Community hospital & \\
\hline & & Other hospital (specify) & \\
\hline & & U.S. hospital & \\
\hline & & Non-U.S. hospital (specify) & \\
\hline & Eligibility criteria & & \\
\hline & & Specified subgroup & \\
\hline & & $\begin{array}{l}\text { (If specified subgroup, is the procedure for } \\
\text { this clear?) }\end{array}$ & \\
\hline
\end{tabular}




\begin{tabular}{|c|c|c|c|}
\hline & & Generalized & \\
\hline & & & MICU \\
\hline & & & SICU/TICU \\
\hline \multicolumn{4}{|l|}{ Interventions } \\
\hline & Complexity & & \\
\hline & & Single/targeted intervention & \\
\hline & & Multicomponent intervention & \\
\hline & Target population & & \\
\hline & & Patients & \\
\hline & & Families & \\
\hline & & Medical providers & \\
\hline & Specification & & \\
\hline & & $\begin{array}{l}\text { Precise details of experimental treatment } \\
\text { provided? }\end{array}$ & \\
\hline & & -tailored to individual? & Timing \\
\hline & & & Frequency \\
\hline & & $\begin{array}{l}\text { How adherence to protocol by providers was } \\
\text { assessed/enhanced? }\end{array}$ & \\
\hline & & & Participants \\
\hline & & & $\begin{array}{l}\text { Components of } \\
\text { communication }\end{array}$ \\
\hline & & & $\begin{array}{l}\text { Details of each } \\
\text { component }\end{array}$ \\
\hline & & $\begin{array}{l}\text { If subgroups targeted, is the procedure for } \\
\text { this clear? }\end{array}$ & \\
\hline \multirow[t]{5}{*}{ Fidelity } & Standardization & & \\
\hline & & $\begin{array}{l}\text { Was any attempt made to standardize the } \\
\text { intervention across providers (e.g., protocol } \\
\text { guidelines, certification, "continue usual } \\
\text { care")? }\end{array}$ & \\
\hline & Adherence & & \\
\hline & & $\begin{array}{l}\text { Did }>80 \% \text { of participants receive the } \\
\text { assigned treatment? }\end{array}$ & \\
\hline & & $\begin{array}{l}\text { Is the reason patients did not received } \\
\text { assigned treatment transparent? }\end{array}$ & \\
\hline
\end{tabular}




\begin{tabular}{|c|c|c|c|}
\hline \multicolumn{4}{|l|}{ Outcomes } \\
\hline & Are there prespecified outcome measures? & & \\
\hline & Type of outcome measures & & \\
\hline & & Utilization-based & \\
\hline & & Family satisfaction-based & \\
\hline & & & Validated tool? \\
\hline & & & Unvalidated tool? \\
\hline & & Family health-based & \\
\hline & & Patient-centered (symptom control, etc.) & \\
\hline & & Patient satisfaction-based & \\
\hline & & Provider satisfaction-based & \\
\hline & & & Validated tool? \\
\hline & & & Unvalidated tool? \\
\hline & & & Physician \\
\hline & & & Nurse \\
\hline & & & Allied health \\
\hline & & Communication and decision-making based & \\
\hline \multicolumn{4}{|c|}{ e } \\
\hline & Any justification of sample size? & & \\
\hline & Response rates to surveys? & Percentage & \\
\hline & Treatment $\mathrm{n}$ & & \\
\hline & & $<50$ & \\
\hline & & $50-99$ & \\
\hline & & $100-499$ & \\
\hline & & $\geq 500$ & \\
\hline & Control $n$ & & \\
\hline & & $<50$ & \\
\hline & & $50-99$ & \\
\hline & & $100-499$ & \\
\hline & & $\geq 500$ & \\
\hline \multicolumn{4}{|l|}{ Blinding } \\
\hline & Patients/families & & \\
\hline & Providers of intervention & & \\
\hline & Providers of co-intervention & & \\
\hline & Data collectors & & \\
\hline
\end{tabular}




\begin{tabular}{|c|c|c|c|}
\hline & Method of blinding described? & & \\
\hline & $\begin{array}{l}\text { If blinded, any discussion about risk of } \\
\text { blinding failure? }\end{array}$ & & \\
\hline & $\begin{array}{l}\text { If not blinded, any attempt to decrease bias or } \\
\text { discussion of potential for bias? }\end{array}$ & & \\
\hline \multicolumn{4}{|l|}{ Participant flow } \\
\hline & $\begin{array}{l}\text { Are there reasons for patients who screen } \\
\text { positive for inclusion not having data } \\
\text { collected or having incomplete data } \\
\text { collection? (e.g., informed consent not } \\
\text { obtained, patient died too quickly, etc.) }\end{array}$ & & \\
\hline & $\begin{array}{l}\text { Are reasons given for deviations from } \\
\text { protocol? }\end{array}$ & & \\
\hline & $\begin{array}{l}\text { Is there any indication of the number of } \\
\text { providers of the intervention? }\end{array}$ & & \\
\hline & $\begin{array}{l}\text { Is there any indication of the number of } \\
\text { patients treated by each provider? }\end{array}$ & & \\
\hline Discussion & Interpretation of results & $\begin{array}{l}\text { Does it describe barriers to implementation } \\
\text { and adaption/other factors that support } \\
\text { success of specific intervention }\end{array}$ & \\
\hline \multirow[t]{2}{*}{ Generalisability } & External validity & $\begin{array}{l}\text { Does it report findings according to } \\
\text { intervention, comparator, patient and care } \\
\text { provider, and centers in the trial? }\end{array}$ & \\
\hline & & $\begin{array}{l}\text { Does it give an overall general interpretation } \\
\text { of results in the context of current evidence? }\end{array}$ & \\
\hline
\end{tabular}


Appendix B Table 2. Critical appraisal tool

\section{Name: \\ PUBH 751: Critical Appraisal of the Health Literature}

Citation (JAMA style)

Study Question and

Research Design

Source Population

Study Population

(descriptive:

demographics, eligibility

criteria) and how chosen

(volunteers, recruitment,

tertiary care clinics,

population-based, etc)

Initial Comparability of

groups (ie,

randomization or group

composition;

concealment of

allocation)

Drop outs (no endpoint

data), adherence,

crossovers (attrition, loss

to follow up)

Potential for selection

bias $(+$ to +++$)$ and

explain

Measurement of

exposure, intervention,

potential confounders,

and outcomes; reliability

and validity of

measurement; how

performed, blinding

Potential for

measurement bias (+ to

$+++)$

Potential confounders

(name and describe how

each was controlled for) 


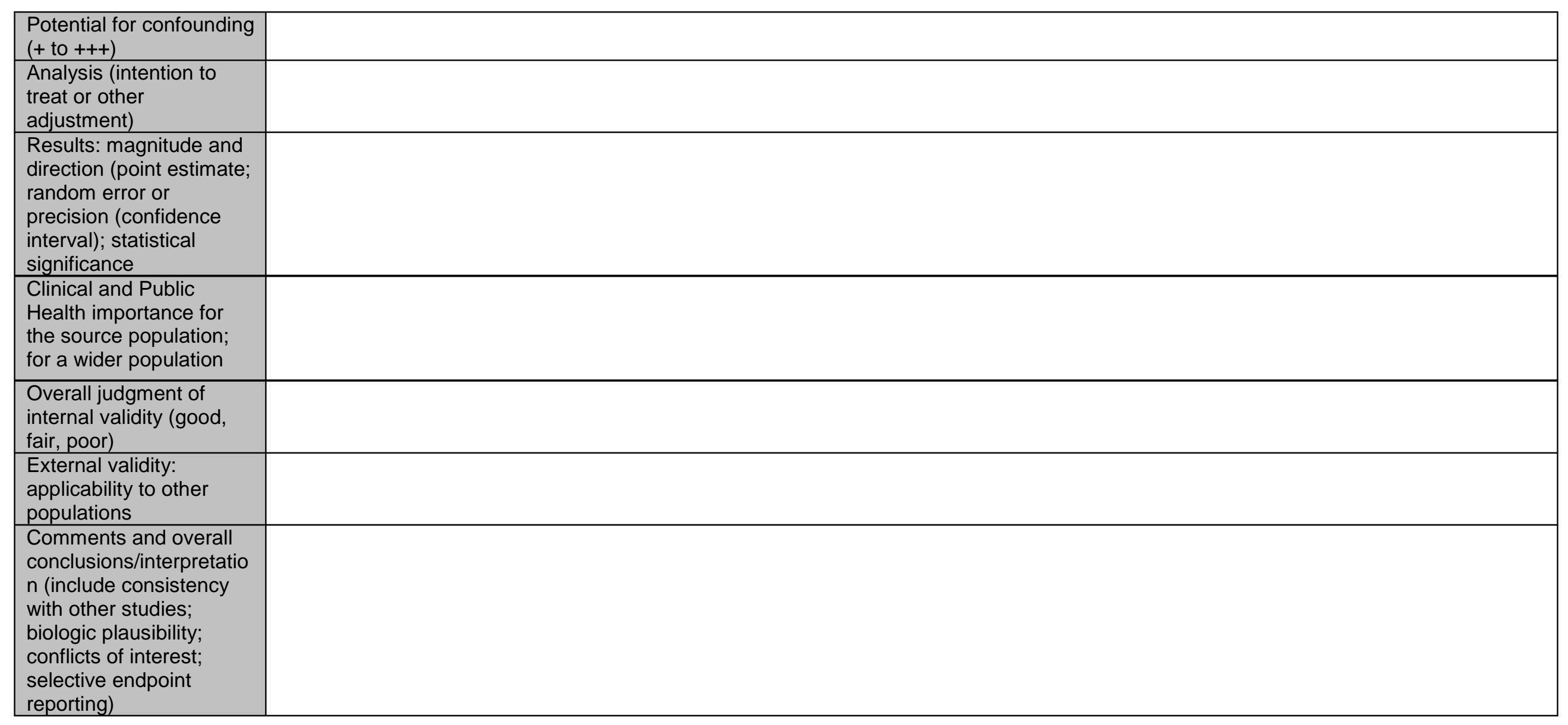




\section{Appendix C: Results}

Further details of the source populations for the intervention group and control group, and the interventions implemented, are provided in Appendix C Table 1. Overall, the study populations were heterogeneous. Researchers had either made a decision that patients on their units were sufficiently ill that all should qualify for regular communication, or had targeted a subset with extremely high mortality.

Although ClinicalTrials.gov does not require the registration of health services research trials like these,$^{60}$ the International Committee of Medical Journal Editors does in order to consider them for publication. ${ }^{61}$ Its increasing use, and the wider acceptance of publication guidelines like CONSORT ${ }^{59}$ and TREND, ${ }^{62}$ will improve assessment of the quality of future studies. For current research, only four of 16 distinct interventions were randomized, making selection bias and the possibility that secular trends influenced the results concerns. Studies had wide variations in the clarity with which they explained the training of the clinicians implementing the interventions, the interventions themselves, and the methods of data collection. A small subset blinded the data collectors to the group to which patients belonged, and many used poorly validated instruments; these factors raised suspicion for measurement bias. High rates of dropout or incomplete data collection occurred in many of the studies. Others failed to report power calculations or prespecify primary outcomes. In all, the possibility for confounding was high in many studies. Thus, few studies were high-quality.

The randomized control trials were overall well-conducted and judged to have fair to good internal validity. Those with historical controls, or enrolling less than 50 subjects, were judged to have limited internal validity. The studies between these extremes were mostly of fair quality. Some red flags occurred, such as when one study of an ethics consultation reported increased 
mortality for the intervention group ${ }^{50}$; determining how to factor these results into our analysis was challenging. We reported the finding and the authors' explanation. As no other studies of ICU communication have found mortality to be increased, it seems unlikely that this finding represents a flaw with the family meeting paradigm. 
Appendix C Table 1. Study Populations, Controls, and Interventions

\begin{tabular}{|c|c|c|c|}
\hline Studies & Intervention Population & Control Population & Intervention \\
\hline \multicolumn{4}{|l|}{ Randomized control trials } \\
\hline Azoulay $^{63}$ & $\begin{array}{l}51 \text { randomly selected French } \\
\text { ICUs (of } 114 \text { total) } \\
\text { Patients patients per ICU with } \\
\text { expected LOS } \geq 48 \mathrm{~h}\end{array}$ & $\begin{array}{l}\text { Randomized-same as } \\
\text { intervention }\end{array}$ & Provision of an informational leaflet \\
\hline Lautrette ${ }^{64}$ & $\begin{array}{l}22 \text { French ICUs } \\
\text { Patients aged } \geq 18 \text { expected by } \\
\text { the attending physician to die } \\
\text { within a few days } \\
\text { French-speaking surrogates }\end{array}$ & $\begin{array}{l}\text { Randomized-same as } \\
\text { intervention }\end{array}$ & $\begin{array}{l}\text { Provision of a bereavement brochure } \\
\text { ICU family conference by the usual ICU team } \\
\text { conducted according to the VALUE mnemonic: } \\
\text { 1) Value and appreciate what family } \\
\text { members said } \\
\text { 2) Acknowledge family members' emotions } \\
\text { 3) Listen } \\
\text { 4) Understand who the patient was as a } \\
\text { person (through specific questioning) } \\
\text { 5) Elicit questions from family members }\end{array}$ \\
\hline Curtis, $^{65}$ Curtis, $^{66}$ and McCormick ${ }^{6 /}$ & $\begin{array}{l}\text { Pilot: ICUs in a } 650 \text {-bed hospital } \\
\text { in Washington } \\
\text { Multi-center: ICUs in } 12 \text { hospitals } \\
\text { in Washington } \\
\text { Patients dying in the ICU or } \\
\text { within } 30 \text { hours of ICU discharge }\end{array}$ & $\begin{array}{l}\text { Pilot: Patients who died prior to } \\
\text { implementation of the } \\
\text { intervention } \\
\text { Multi-center: Cluster } \\
\text { randomized by study site-- } \\
\text { similar patients at control } \\
\text { hospitals }\end{array}$ & $\begin{array}{l}\text { Quality improvement intervention targeting } 5 \\
\text { components: } \\
\text { 1) Clinician education } \\
\text { 2) Local champions } \\
\text { 3) Academic detailing } \\
\text { 4) Clinician feedback of quality data } \\
\text { 5) System supports }\end{array}$ \\
\hline Schneiderman ${ }^{43}$ and Schneiderman ${ }^{42}$ & $\begin{array}{l}\text { Pilot: Medical and pediatric ICU } \\
\text { patients at one academic center } \\
\text { Multi-center: Adult ICUs at } 7 \\
\text { diverse medical centers } \\
\text { Patients for whom value-based } \\
\text { treatment conflicts arose }\end{array}$ & $\begin{array}{l}\text { Randomized-same as } \\
\text { intervention }\end{array}$ & $\begin{array}{l}\text { Offer of an ethics consultation within } 24 \text { hours of } \\
\text { randomization. } \\
\text { General process of ethics consultation: } \\
\text { 1) Consultation request } \\
\text { 2) Assessment of request } \\
\text { 3) Ethical diagnosis } \\
\text { 4) Recommendations for next steps } \\
\text { 5) Documentation of consultation } \\
\text { 6) Follow-up support } \\
\text { 7) Evaluation pre study protocol } \\
\text { 8) Record-keeping to enhance future } \\
\text { practice improvement } \\
\end{array}$ \\
\hline
\end{tabular}




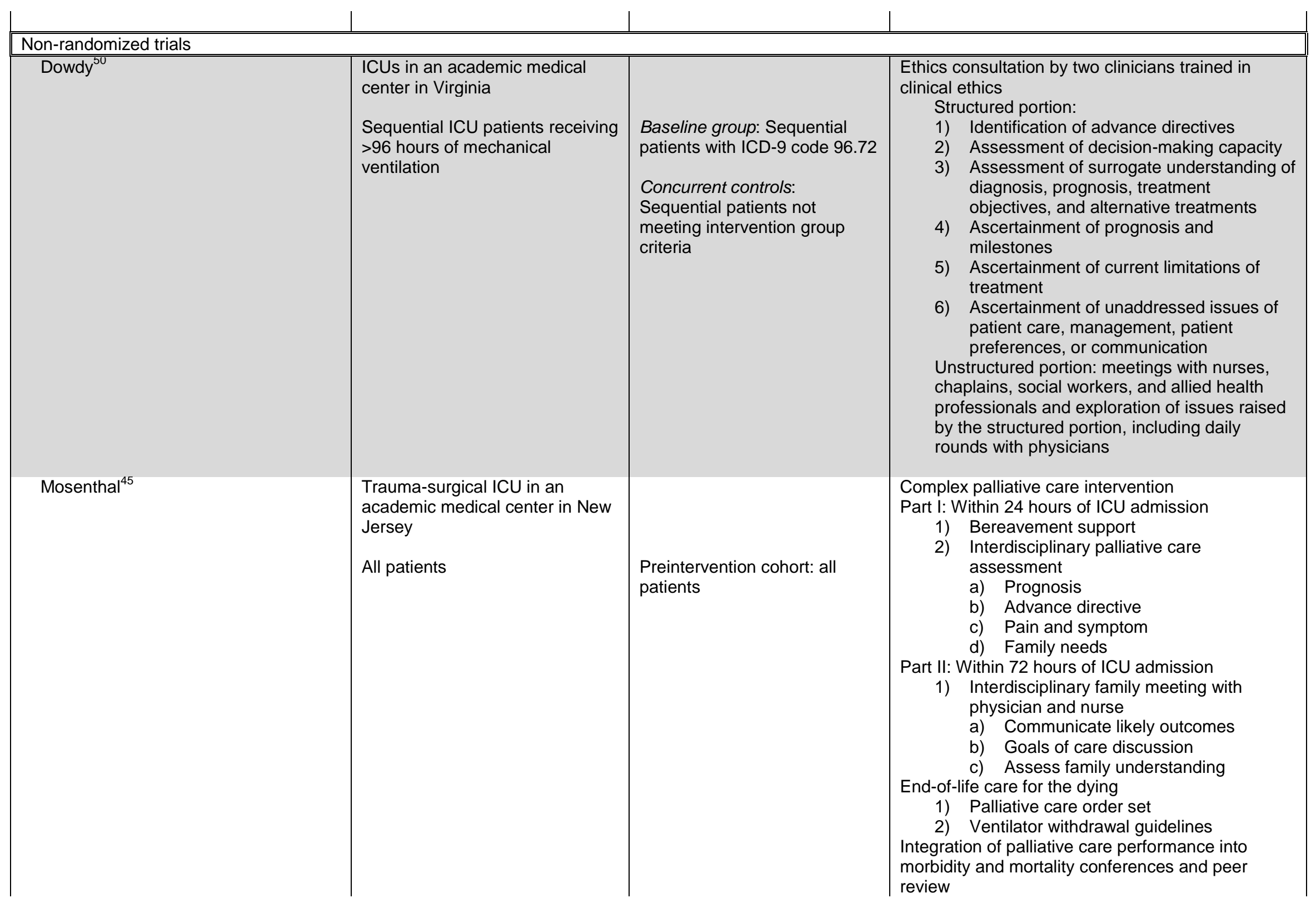




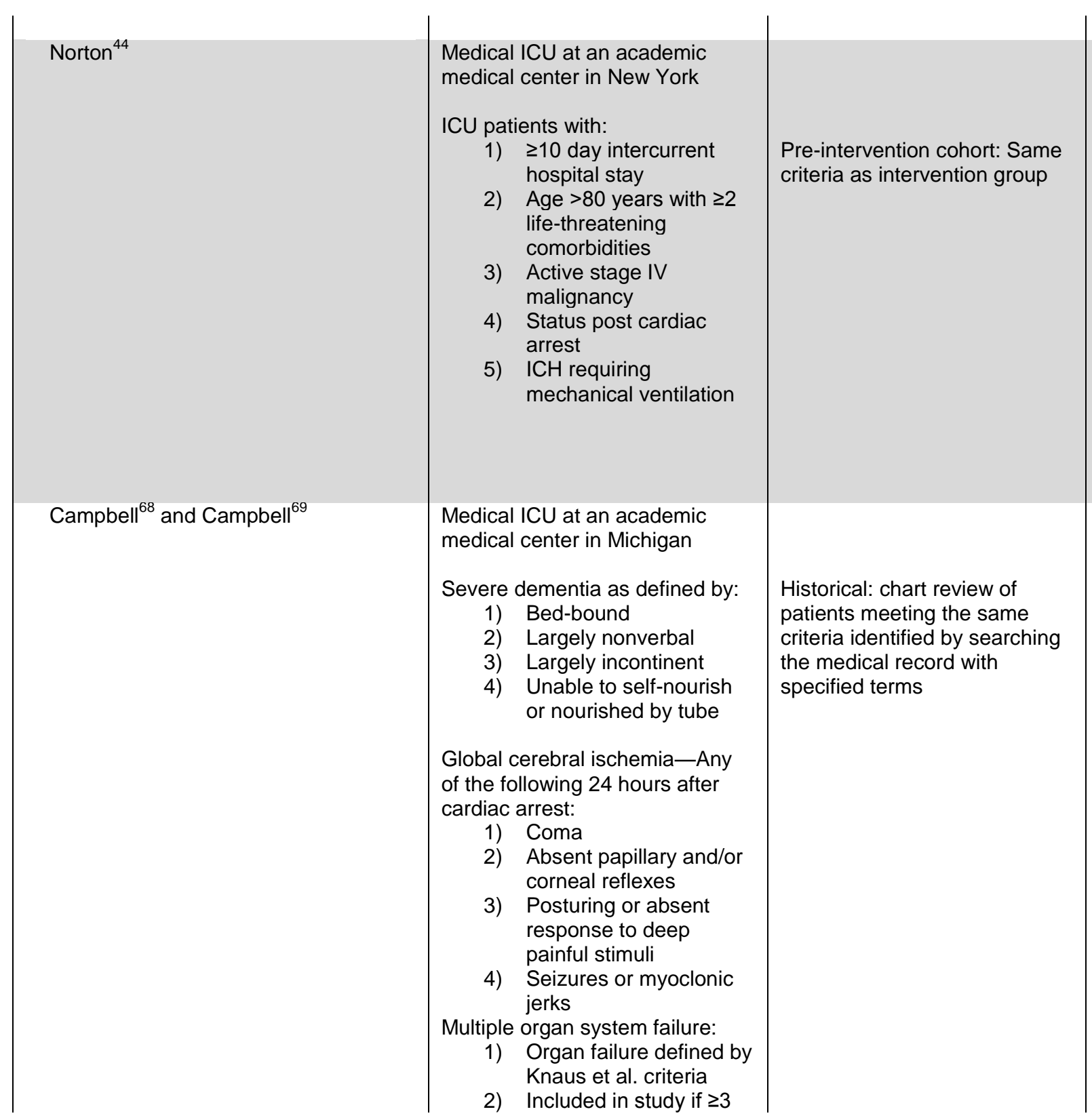

Palliative care consultation

Basic:

1) Chart review

2) Brief HPI and physical exam with symptom assessment

3) Discussion with medical, nursing, and social work regarding symptom control and decision-making

4) Discussion and review of recommendations

5) Documentation

Complete (triggered by unaddressed need):

1) Full involvement of palliative care attending

2) Regular family meetings

3) Regular review of goals of care

4) Involvement of other support members of the palliative care team (e.g., chaplain)

Palliative care consultation

Dementia:

1) Early communication of prognosis

2) Identification of advance directives

3) Assistance with discussing goals of care

4) Implementation of palliative care strategies when appropriate

5) Education of the primary team Global cerebral ischemia:

1) Family meeting on 2nd MICU day (after EEG)

2) If poor prognosis confirmed on $3^{\text {rd }} \mathrm{MICU}$ day, recommend change of goals to palliation

3) Daily meetings until patient changed to comfort care

4) Palliative care support provided

Multiple organ system failure:

1) Assess family understanding of prognosis

2) Daily family meetings to recommend changing goals of care to palliation 


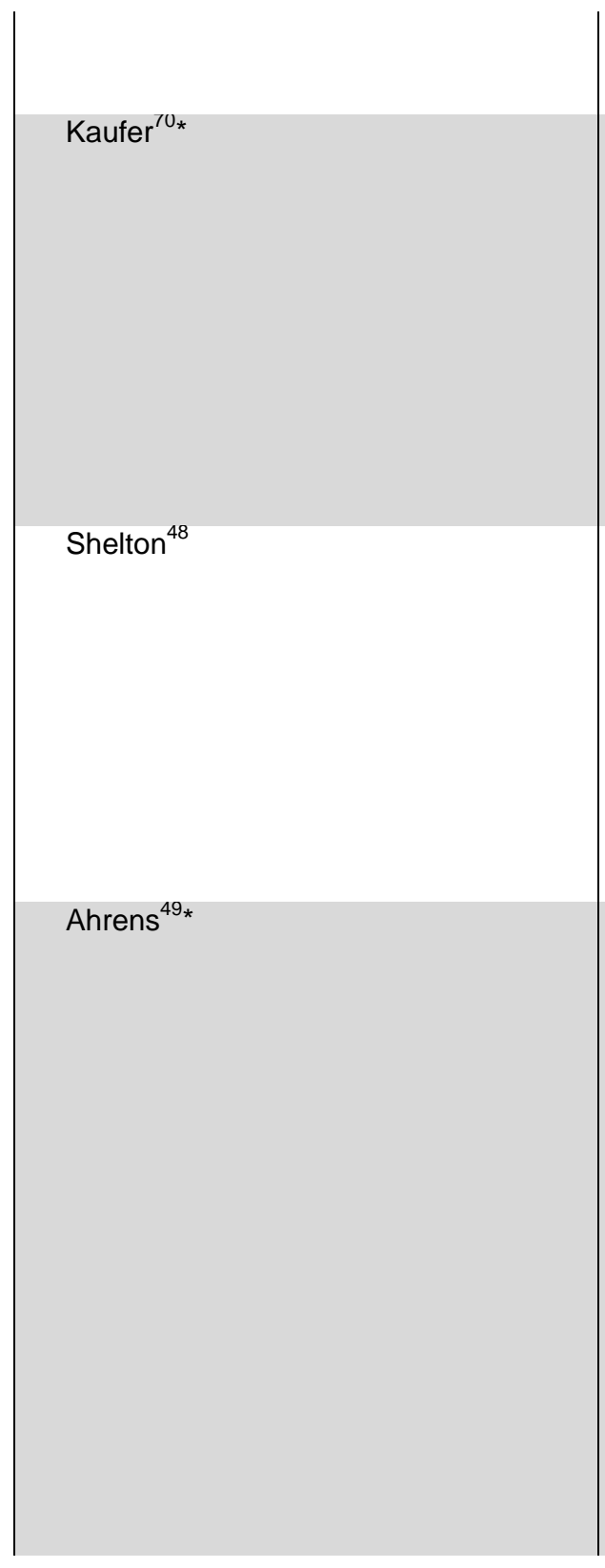

\begin{tabular}{|c|c|c|}
\hline \multicolumn{2}{|c|}{$\begin{array}{l}\text { failed systems for } \geq 3 \\
\text { davs }\end{array}$} & \\
\hline \multicolumn{2}{|c|}{ ICU patients who died } & $\begin{array}{l}\text { Pre-intervention group: Same } \\
\text { criteria as the intervention } \\
\text { group }\end{array}$ \\
\hline \multicolumn{2}{|c|}{$\begin{array}{l}\text { Surgical ICU at an academic } \\
\text { medical center in New York }\end{array}$} & \\
\hline \multicolumn{2}{|c|}{$\begin{array}{l}\text { Patients expected by the } \\
\text { attending to be in the ICU at day } \\
5 \text { (measured at day 2) }\end{array}$} & $\begin{array}{l}\text { Pre-intervention group: Same } \\
\text { criteria as the intervention } \\
\text { group }\end{array}$ \\
\hline \multicolumn{2}{|c|}{$\begin{array}{l}\text { Medical ICU at an academic } \\
\text { medical center in Missouri }\end{array}$} & \multirow{7}{*}{$\begin{array}{l}\text { Non-concurrent controls: } \\
\text { Same as the intervention } \\
\text { group enrolled when medical } \\
\text { director off service }\end{array}$} \\
\hline \multicolumn{2}{|c|}{ ICU patients with: } & \\
\hline 2) & $\begin{array}{l}\text { Conditions associated } \\
\text { with an unacceptable } \\
\text { QOL }\end{array}$ & \\
\hline 3) & $\begin{array}{l}\text { Imminent demise } \\
\text { (APACHE score risk } \\
>80 \%)\end{array}$ & \\
\hline 4) & $\begin{array}{l}\text { Lethal condition (lack of } \\
\text { success of } 1^{\text {st }} \text { line } \\
\text { therapy) }\end{array}$ & \\
\hline 5) & $\begin{array}{l}\text { Mechanical ventilation } \\
>3 \text { davs }\end{array}$ & \\
\hline 6) & $\begin{array}{l}\text { Prehospitalization } \\
\text { NYHA class IV heart }\end{array}$ & \\
\hline
\end{tabular}

3) Palliative care support provided when comfort care instituted

Palliative care consultation

1) Rounded with ICU team at least 3 times a week

2) Held educational initiatives for ICU team members

Family support team

1) Rounded with the ICU team at least 3 times a week

2) Held educational initiatives for ICU team members

3) Facilitated family meetings

4) Ensured documentation

Family support coordinator (an experienced ICU nurse, overall goal to provide a stable liaison between family and ICU team):

1) Assess family's information needs

2) Interpret medical information

3) Assist the family in processing the information

4) Identify need for and connect with members of the interdisciplinary team

5) Enhance the medical team's understanding of family's needs

Two ICU clinical nurse specialists and the medical director provided:

1) Daily medical updates to patient families

2) Guidelines and recommendations for treatment

3) Emotional and informational support

4) Educational opportunities for unit staff on palliative care 


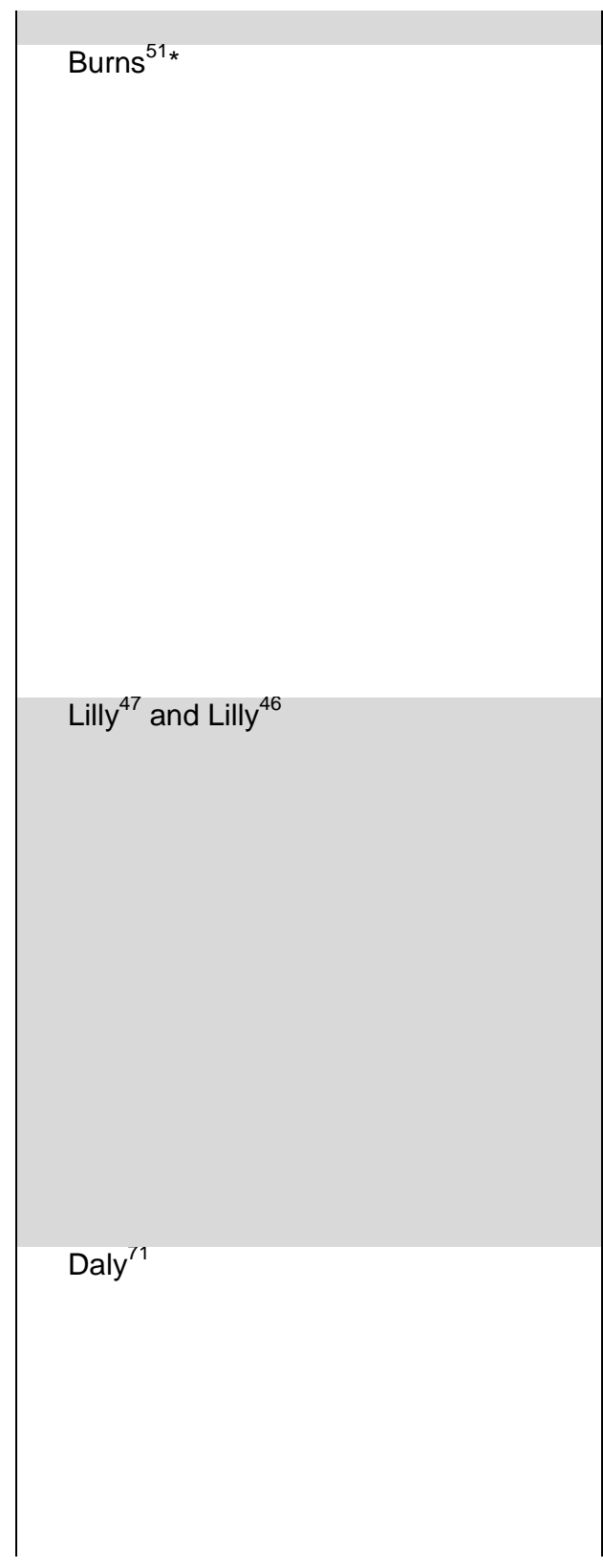

failure or LVEF <20\%

4 surgical and 3 medical ICUs in academic medical centers in

Massachusetts

ICU patients:

1) Lacking decisional capacity and an identified surrogate

2) Experiencing decisional conflict

3) Exceeding the $85^{\text {th }}$ percentile for length of stay

4) Admitted to the ICU for an iatrogenic event

English-speaking patients and surrogates

\section{Medical ICU patients at an}

academic medical center in

Masachusetts

\section{All ICU patients}

2 surgical, 1 medical, and 1

neuroscience ICU at a university affiliated hospital and an

academic medical center in Ohio

\section{CU patients:}

1) Receiving $>72$ hours of mechanical ventilation and not expected to be
Nonrandomized concurrent: the next discharged patient from the ICU who had not screened positive for

enrollment
Pre-intervention controls

Same as intervention group

Pre-intervention controls:

Same criteria as intervention

\section{Social work-led intervention:}

1) Screen for cases at high risk for decisional conflict

2) Interview family

a) Elicit patient and surrogate perceptions of care and conflicts

b) Focus on communication, information-giving, psychosocial support

3) Feedback to the clinical team

4) Assist deliberations

5) Provide and elicit treatment recommendations

Multidisciplinary family meetings by the usual ICU team within 72 hours of admission:

1) Conducted by attending physician if:

a) Predicted LOS $\geq 5$ days

b) Predicted mortality $>25 \%$ judged by attending

c) Potential change in functional status precluding return home

2) Objectives of meetings:

a) Review medical facts and treatment options

b) Discuss patient values

c) Agree on a care plan

d) Agree how the success or failure of the care plan will be judged

3) Weekly multidisciplinary case review

Two advance practice nurses facilitated

communication:

1) Schedule family meetings

2) Ensure consistency of family meetings Communication structure:

1) Family meeting held within 5 days of admission and at least weekly thereafter

2) Each meeting involved medical update patient values, goals of care, treatment 


\begin{tabular}{|c|c|c|c|}
\hline & $\begin{array}{ll} & \text { liberated or discharged } \\
& \text { in the next } 48 \text { hours } \\
\text { 2) } & \text { Lacking decisional } \\
\text { capacity } \\
\text { 3) Not on mechanical } \\
\text { ventilation prior to } \\
\text { admission } \\
\text { 4) Having an identified } \\
\text { surrogate } \\
\text { Surrogates: } \\
\text { 1) Identified as the } \\
\text { appropriate surrogate } \\
\text { 2) Available for family } \\
\text { meetings }\end{array}$ & & $\begin{array}{l}\text { plan, and criteria for determining } \\
\text { effectiveness of treatment plan }\end{array}$ \\
\hline Steel $^{\prime 2}$ & $\begin{array}{l}\text { Critical Care Unit at a District } \\
\text { General Hospital in England } \\
\text { All surrogates during the study } \\
\text { period }\end{array}$ & $\begin{array}{l}\text { Pre-intervention and post- } \\
\text { intervention controls: Same } \\
\text { criteria as intervention }\end{array}$ & $\begin{array}{l}\text { Offer of a family support clinic (families signed up } \\
\text { in an appointment book in the waiting room) } \\
\text { 1) Held between } 2 \mathrm{pm} \text { and } 3 \mathrm{pm} \text { on weekdays } \\
\text { 2) Held in the unit "quiet room" } \\
\text { 3) Conducted by the physician who knew the } \\
\text { patient best and the nurse who was caring } \\
\text { for the patient at the time of the meeting }\end{array}$ \\
\hline Medland ${ }^{73}$ & $\begin{array}{l}\text { Medical ICU at an academic } \\
\text { medical center in Illinois } \\
\\
\text { Surrogates who: } \\
\text { 1) Had a relative admitted } \\
\text { to the ICU within the } \\
\text { past } 24 \text { hours } \\
\text { 2) Were identified as the } \\
\text { surrogate } \\
\text { 3) Had access to a } \\
\text { telephone } \\
\text { 4) Agreed to keep a } \\
\text { scheduled telephone } \\
\text { appointment }\end{array}$ & $\begin{array}{l}\text { Pre-intervention controls: } \\
\text { Same criteria as intervention }\end{array}$ & $\begin{array}{l}\text { Usual care: } \\
\text { 1) Provision of standard informational } \\
\text { booklet } \\
\text { 2) Report of patient status as fair, serious or } \\
\text { critical by clerk on telephone inquiry } \\
\text { Intervention: } \\
\text { 1) Meeting with a nurse approximately } 24 \\
\text { hours after admission } \\
\text { 2) Provision of a specially developed } \\
\text { pamphelet } \\
\text { 3) Daily telephone updates by the ICU nurse }\end{array}$ \\
\hline
\end{tabular}

AIDS acquired immunodeficiency syndrome; APACHE acute physiology and chronic health evaluation; ICH Intracerabral hemorrhage; ICU intensive care unit; NYHA New York Heart Association; LVEF Left ventricular ejection fraction; QOL quality of life

*patients included if they were able to participate 


\section{Appendix D: Discussion}

This systematic review synthesized the evidence since SUPPORT ${ }^{52}$ for interventions that could improve ICU communication. As a whole, this foundational work represents important efforts to reduce delivery of care that patients would not value it, to reduce the number who experience protracted deaths, to provide emotional support to families, and to reduce ICU costs. When aggregated, they demonstrate moderately strong evidence that printed information to improves family comprehension and that structured family conferences conducted by the usual ICU team, ethics consultation, or palliative care consultation to improve patient and family centered outcomes, including emotional distress, processes of communication, and the frequency and timing of decisions about major treatments.

\section{Revisiting ICU patient vulnerabilities}

The interventions in this systematic review addressed patient-related vulnerabilities poorly. Three studies would have permitted ICU patients with decision-making capacity to participate ${ }^{49,51,70}$ but none reported any outcomes related to patient participation. Although too few ICU patients have the capacity to participate in decision-making to achieve statistical power, it may be beneficial for some future studies to report the extent of patients' participation and any challenges it posed. Otherwise, the paucity of patient-centered outcomes from these studies suggests that defining and measuring such outcomes presents special challenges. Unfortunately, symptom burdens were only investigated in the cluster-randomized trial of palliative care quality improvement, in which they were unchanged. The most consistent patient-centered outcome reported was mortality. Intensity of treatment and length of stay have a poorly defined role as patient-centered outcomes; they must be compared to patient preferences to be interpreted and patient preferences were not measured. Qualitative research with ICU survivors may reveal factors that patients feel are important in surrogate decisionmaking for them. 
However, two interventions did investigate and improve the emotional distress families of ICU patients face. The one investigating anxiety and depression as a secondary outcome of receiving an informational pamphlet found no change in these outcomes. ${ }^{63}$ However, the one investigating post-traumatic stress and anxiety and depression as its primary outcome after provision of printed information and structured family conferences did find significant improvement. ${ }^{64}$ This finding suggests that information alone does not affect emotional outcomes, but supportive, personalized communication can.

Ethical factors related to decision-making remain unclear. As several of the interventions used ethics committees to facilitate communication, the importance of ethics to decision-making is clear. The incorporation of ethical principles in decision-making was stated in the study procedures, although few studies explained how they approached it. None reported specifically ethics-related outcomes.

\section{Revisiting provider perspectives}

One reviewed study evaluated provider satisfaction with the intervention. ${ }^{42}$ Although satisfaction was high, the studies failed to measure satisfaction in a control group of providers, so the efficacy of the intervention to improve provider satisfaction is unknown. One study demonstrated lower rates of decisional conflict among providers. ${ }^{46}$ Another suggested lower stress among nurses having to field fewer telephone calls from family members. ${ }^{73}$ Taken together, these outcomes suggest that family communication interventions in the ICU have potential benefits for providers. Investigating their ability to reduce burn-out or compassion fatigue and to improve confidence in ethical and patient-centered care remains an important goal for future research. Additionally, providers may have an important role in assessing patient comfort, quality of communication with families, quality of care, and other key outcomes. 


\section{Revisiting health system factors}

The hope that communications interventions in the ICU might curtail resource utilization requires further specification. When system-wide costs are considered, ICU communications interventions are unlikely to have significant impact. Approximately $80 \%$ of ICU costs are fixed, meaning they accrue from the physical facility, personnel salaries, and administrative costs. ${ }^{37}$ Variable costs only represent $20 \%$ of patient costs, and the majority accumulate within the first 48 hours of a patient's stay, when decision-making is just beginning. For patients who are transferred elsewhere after a decision to de-escalate care, their charges are shifted to other parts of the system but are not substantially less.

However, because ICU beds and technologies are scarce resources, transferring these patients out of the ICU will allow patients who will potentially derive greater health benefit to use them. Thus, although the total use of resources is not decreased, the resources are used more effectively under this distribution. Additionally, the cost-effectiveness and efficiency of care for ICU patients can potentially improve with communication because unwanted care is not costeffective or efficient by definition. In these ways, reduced use of life-sustaining treatments and reduced lengths of stay can benefit the patient targeted by communication and other patients within the system. Our systematic review suggests that family conferences in the ICU may contribute to these changes.

\section{Overcoming methodological limitations}

However, future work should avoid some common methodological weaknesses. Because culture in the ICU evolves rapidly, secular trends are likely to influence family communication there. Separating the effect of secular trends from the intervention effects in studies with historical controls or in studies of pre-post design is impossible. Yet, ten interventions in our 
systematic review used these designs. Stronger designs that avoid this complication, most importantly RCTs, should become standard in this field.

Furthermore, the variety of outcome instruments, and the variability in their validation, impedes understanding and comparing results across studies. Research testing outcomes with adequate existing instruments should utilize them. For those outcomes with multiple available instruments, the one with the best combination of clinical importance and strong psychometric properties should be determined and become standard. However, the lack of available outcome instruments should not deter researchers from investigating important novel outcomes. They should rigorously develop such instruments in preliminary work and then evaluate the effect of interventions on them.

Unfortunately high rates of missing data or of drop-outs may continue to plague these interventions because of the challenges of patient transitions and mortality. Researchers should anticipate this difficulty in collecting future data and ensure that important outcome data can be collected during the index hospitalization.

\section{Directions for future innovation}

Although addressing the problems of ICU communication was set back by the results of SUPPORT, ${ }^{52}$ current evidence sufficiently demonstrates that printed information and family conferences are effective at improving important outcomes. Research should expand the questions it asks from simple investigation of printed information or conferences. Instead, it should evaluate specific subpopulations of ICU patients with particularly unambiguous poor mortality or functional outcomes, such as those with chronic critical illness. Furthermore, it should ask how prognosis can be effectively communicated, how providers can elicit authentic patient values from surrogates, and how surrogates and providers can best accomplish shared 
decision-making. Finally, is should standardize use of previously validated outcome measurement tools when they are available, but also seek novel patient- and family-centered outcomes and develop rigorous methods of measuring them as well.

The quality and quantity of observational evidence characterizing communication with surrogates in ICUs has exploded in recent years. ${ }^{74-79}$ Continuing to build it and incorporating it into the next stages of interventions is essential. For example, qualitative data published within the last three years (since most of the interventions reported in this work were initiated) has established that surrogates expect accurate prognostication from physicians and find sources of hope elsewhere ${ }^{77}$; that surrogates have variable belief in physicians' ability to prognosticate ${ }^{78}$; and that at least $20 \%$ of physicians specifically asked for a treatment recommendation from surrogates remain unwilling to provide one. ${ }^{74}$

Surrogate communication in the ICU could be informed by many areas of social science. Psychology, social psychology, behavioral economics, bioethics, information science, health literacy, anthropology, and sociology all have potential relevance. To date, we are only aware of ethnographic studies from anthropology describing ICU communication. ${ }^{80}$ However, the methodologies of these sciences may provide powerful vehicles for modeling, measuring, and intervening on ICU communication. In the future, providers of ICU care should explore opportunities for such collaboration.

\section{Conclusions}

Value-based decision-making for ICU patients is complicated. Surrogates lack guidance by applicable advance directives, and face emotional and cognitive stressors, including an acute life-and-death decision. Providers must clearly communicate diagnosis, prognosis, treatment options, and norms of ICU care. Both are challenged by time barriers, dynamic situations, and 
basic problems of communicating effectively and compassionately. However, our systematic review provides moderate evidence that family comprehension improves with provision of printed information. Additionally, family emotional outcomes, the quality of communication, and the frequency and timing of interventions improves with regular, structured communication by the regular ICU team, ethics consultation, or palliative care consultation. These findings provide a solid foundation for future efforts to continue to improve patient-and-family centered care in the ICU. 


\section{References}

1. Barnard R. Indiscriminate transfusion: a critique of case reports illustrating hypersensitivity reactions. New York state journal of medicine. 1951;51(20):2399.

2. Schito G. The importance of the development of antibiotic resistance in Staphylococcus aureus. Clinical Microbiology and Infection. 2006;12:3-8.

3. Danis M, Truog R, DeVita M, Lynn J, Sprung C. Consensus statement of the Society of Critical Care Medicine's Ethics Committee regarding futile and other possibly inadvisable treatments. Crit Care Med. 1997;25:887-891.

4. Hopkins R, Weaver L, Collingridge D, Parkinson R, Chan K, Orme Jr J. Two-year cognitive, emotional, and quality-of-life outcomes in acute respiratory distress syndrome. American Journal of Respiratory and Critical Care Medicine. 2005;171(4):340.

5. Rubenfeld G, Herridge M. Epidemiology and Outcomes of Acute Lung Injury*. Chest. 2007;131(2):554.

6. Hofhuis J, Spronk P, van Stel H, Schrijvers G, Rommes J, Bakker J. The Impact of Critical Illness on Perceived Health-Related Quality of Life During ICU Treatment, Hospital Stay, and After Hospital Discharge*. Chest. 2008;133(2):377.

7. Kennedy I. The Karen Quinlan case: problems and proposals. Journal of medical Ethics. 1976;2(1):3.

8. Fletcher J. The bioethics movement and hospital ethics committees. Maryland law review (Baltimore, Md.: 1936). 1991;50(3):859.

9. Field M, Cassel C. Approaching death: Improving care at the end of life. Palliative Care: Transforming the Care of Serious Illness. 2010:79.

10. Stapleton R, Wang B, Hudson L, Rubenfeld G, Caldwell E, Steinberg K. Causes and Timing of Death in Patients With ARDS*. Chest. 2005;128(2):525.

11. Prendergast $\mathrm{T}$, Claessens $\mathrm{M}$, Luce J. A national survey of end-of-life care for critically ill patients. American Journal of Respiratory and Critical Care Medicine. 1998;158(4):1163.

12. Danis $M$, Federman $D$, Fins J, et al. Incorporating palliative care into critical care education: Principles, challenges, and opportunities. Critical Care Medicine. 1999;27(9):2005.

13. Jones $\mathrm{G}$, Brewer K, Garrison H. Public expectations of survival following cardiopulmonary resuscitation. Academic Emergency Medicine. 2000;7(1):48-53.

14. Vig E, Taylor J, Starks H, Hopley E, Fryer Edwards K. Beyond Substituted Judgment: How Surrogates Navigate End of Life Decision Making. Journal of the American Geriatrics Society. 2006;54(11):1688-1693.

15. Childress J, Beauchamp T. Principles of biomedical ethics. New York: Oxford University. 2009.

16. Happ M, Tuite P, Dobbin K, DiVirgilio-Thomas D, Kitutu J. Communication ability, method, and content among nonspeaking nonsurviving patients treated with mechanical ventilation in the intensive care unit. American Journal of Critical Care. 2004;13(3):210.

17. Jacobi J, Fraser G, Coursin D, et al. Clinical practice guidelines for the sustained use of sedatives and analgesics in the critically ill adult. Critical care medicine. 2002;30(1):119.

18. Morris P. Moving our critically ill patients: mobility barriers and benefits. Critical care clinics. 2007;23(1):1-20.

19. Nelson J, Meier D, Oei E, et al. Self-reported symptom experience of critically ill cancer patients receiving intensive care. Critical care medicine. 2001;29(2):277.

20. Cook D, Guyatt G, Rocker G, et al. Cardiopulmonary resuscitation directives on admission to intensive-care unit: An international observational study. The Lancet. 2001;358(9297):19411945. 
21. Goodman M, Tarnoff M, Slotman G. Effect of advance directives on the management of elderly critically ill patients. Critical care medicine. 1998;26(4):701.

22. Fagerlin A, Schneider C. Enough: The Failure of the Living Will. The Hastings Center Report. 2004;34(2):30-43.

23. Nelson J, Angus D, Weissfeld L, et al. End-of-life care for the critically ill: A national intensive care unit survey*. Critical care medicine. 2006;34(10):2547.

24. Azoulay E, Pochard F, Kentish-Barnes N, et al. Risk of posttraumatic stress symptoms in family members of intensive care unit patients. American journal of respiratory and critical care medicine. 2005:200409.

25. Anderson W, Arnold R, Angus D, Bryce C. Posttraumatic stress and complicated grief in family members of patients in the intensive care unit. Journal of general internal medicine. 2008;23(11):1871-1876.

26. Pochard F, Darmon M, Fassier $\mathrm{T}$, et al. Symptoms of anxiety and depression in family members of intensive care unit patients before discharge or death. A prospective multicenter study. Journal of critical care. 2005;20(1):90-96.

27. Azoulay $\mathrm{E}$, Chevret $\mathrm{S}$, Leleu $\mathrm{G}$, et al. Half the families of intensive care unit patients experience inadequate communication with physicians. Critical Care Medicine. 2000;28(8):3044.

28. Buchanan A, Brock D. Deciding for others: the ethics of surrogate decision making: Cambridge Univ Pr; 1989.

29. Shalowitz D, Garrett-Mayer E, Wendler D. The accuracy of surrogate decision makers: a systematic review. Archives of Internal Medicine. 2006;166(5):493.

30. Sorensen R, ledema R. Advocacy at end-of-life:: Research design: An ethnographic study of an ICU. International journal of nursing studies. 2007;44(8):1343-1353.

31. Facing Death. PBS. November 10,2010, 2010.

32. Curtis J, Rubenfeld G. Managing death in the ICU: the transition from cure to comfort: Oxford University Press, USA; 2001.

33. Embriaco N, Azoulay E, Barrau K, et al. High level of burnout in intensivists: prevalence and associated factors. American journal of respiratory and critical care medicine. 2007:200608.

34. Hamric A, Blackhall L. Nurse-physician perspectives on the care of dying patients in intensive care units: Collaboration, moral distress, and ethical climate*. Critical care medicine. 2007;35(2):422.

35. Meltzer L, Huckabay L. CRITICAL CARE NURSES'PERCEPTIONS OF FUTILE CARE AND ITS EFFECT ON BURNOUT. American Journal of Critical Care. 2004;13(3):202.

36. Poncet $\mathrm{M}$, Toullic $\mathrm{P}$, Papazian $\mathrm{L}$, et al. Burnout syndrome in critical care nursing staff. American Journal of Respiratory and Critical Care Medicine. 2007;175(7):698.

37. Luce J, Rubenfeld G. Can health care costs be reduced by limiting intensive care at the end of life? American journal of respiratory and critical care medicine. 2002;165(6):750.

38. Hogan C, Lunney J, Gabel J, Lynn J. Medicare beneficiaries' costs of care in the last year of life. Health Affairs. 2001;20(4):188.

39. Burchardi $\mathrm{H}$, Schneider $\mathrm{H}$. Economic aspects of severe sepsis: a review of intensive care unit costs, cost of illness and cost effectiveness of therapy. Pharmacoeconomics. 2004;22(12):793813.

40. Shorr A. An update on cost-effectiveness analysis in critical care. Current Opinion in Critical Care. 2002;8(4):337.

41. Talmor D, Shapiro N, Greenberg D, Stone P, Neumann P. When is critical care medicine costeffective? A systematic review of the cost-effectiveness literature*. Critical care medicine. 2006;34(11):2738. 
42. Schneiderman L, Gilmer $\mathrm{T}$, Teetzel $\mathrm{H}$. Impact of ethics consultations in the intensive care setting: a randomized, controlled trial. Critical care medicine. 2000;28(12):3920.

43. Schneiderman L, Gilmer T, Teetzel H, et al. Effect of ethics consultations on nonbeneficial lifesustaining treatments in the intensive care setting: a randomized controlled trial. Jama. 2003;290(9):1166.

44. Norton S, Hogan L, Holloway R, Temkin-Greener H, Buckley M, Quill T. Proactive palliative care in the medical intensive care unit: effects on length of stay for selected high-risk patients. Critical Care Medicine. 2007;35(6):1530.

45. Mosenthal A, Murphy P, Barker L, Lavery R, Retano A, Livingston D. Changing the culture around end-of-life care in the trauma intensive care unit. The Journal of Trauma. 2008;64(6):1587.

46. Lilly C, De Meo D, Sonna L, et al. An intensive communication intervention for the critically ill* 1 . The American journal of medicine. 2000;109(6):469-475.

47. Lilly C, Sonna L, Haley K, Massaro A. Intensive communication: Four-year follow-up from a clinical practice study. Critical care medicine. 2003;31(5):S394.

48. Shelton W MC, Socaris S, Gao J, Dowling J. The effect of a family support intervention on family satisfaction, length-of-stay, and cost of care in the intensive care unit. Crit Care Med. 2010;38(5):6.

49. Ahrens $\mathrm{T}$, Yancey V, Kollef M. Improving family communications at the end of life: implications for length of stay in the intensive care unit and resource use. American Journal of Critical Care. 2003;12(4):317.

50. Dowdy D, Eid M, Sedrakyan A, et al. Quality of life in adult survivors of critical illness: a systematic review of the literature. Intensive care medicine. 2005;31(5):611-620.

51. Burns J, Mello M, Studdert D, Puopolo A, Truog R, Brennan T. Results of a clinical trial on care improvement for the critically ill. Critical Care Medicine. 2003;31(8):2107.

52. Connors A, Dawson N, Desbiens N, Fulkerson W, Goldman L, Harrell F. A controlled trial to improve care for seriously ill hospitalized patients. Jama. 1995;274(20):1591-1598.

53. Heyland D, Cook D, Rocker G, et al. Decision-making in the ICU: Perspectives of the substitute decision-maker. Intensive care medicine. 2003;29(1):75-82.

54. Stapleton R, Engelberg R, Wenrich M, Goss C, Curtis J. Clinician statements and family satisfaction with family conferences in the intensive care unit*. Critical care medicine. 2006;34(6):1679.

55. McDonagh J, Elliott T, Engelberg R, et al. Family satisfaction with family conferences about endof-life care in the intensive care unit: Increased proportion of family speech is associated with increased satisfaction*. Critical care medicine. 2004;32(7):1484.

56. Curtis J, Patrick D, Shannon S, Treece P, Engelberg R, Rubenfeld G. The family conference as a focus to improve communication about end-of-life care in the intensive care unit: opportunities for improvement. Critical Care Medicine. 2001;29(2):N26.

57. Nelson J, Mulkerin C, Adams L, Pronovost P. Improving comfort and communication in the ICU: A practical new tool for palliative care performance measurement and feedback. Quality and Safety in Health Care. 2006;15(4):264.

58. Truog R, Campbell M, Curtis J, et al. Recommendations for end-of-life care in the intensive care unit: a consensus statement by the American College of Critical Care Medicine. Critical Care Medicine. 2008;36(3):953.

59. Altman $\mathrm{D}$, Schulz $\mathrm{K}$, Moher $\mathrm{D}$, et al. The revised CONSORT statement for reporting randomized trials: explanation and elaboration. Annals of internal medicine. 2001;134(8):663.

60. Health USNIo. www.clinicialtrials.gov. Accessed November 30,2010. 
61. De Angelis C, Drazen J, Frizelle F, et al. Clinical trial registration: a statement from the International Committee of Medical Journal Editors. Annals of internal medicine. 2004;141(6):477.

62. Des Jarlais D, Lyles C, Crepaz N. Improving the reporting quality of nonrandomized evaluations of behavioral and public health interventions: the TREND statement. American Journal of Public Health. 2004;94(3):361.

63. Azoulay E, Pochard F, Chevret S, et al. Impact of a family information leaflet on effectiveness of information provided to family members of intensive care unit patients. A multicenter, prospective, randomized, controlled trial. American journal of respiratory and critical care medicine. 2002;165(4):438.

64. Lautrette A, Darmon M, Megarbane B, et al. A communication strategy and brochure for relatives of patients dying in the ICU. The New England journal of medicine. 2007;356(5):469.

65. Curtis JR NE, Treece PD, Downey L, Dotolo D, Shannon SE, Back AL, Rubenfeld GD, Engelberg RA. Effect of a Quality-Improvement Intervention on End-of-Life Care in the Intensive Care Unit: A Randomized Trial. Am J Respir Crit Care Med. 2010.

66. Curtis J, Treece $P$, Nielsen $E$, et al. Integrating palliative and critical care: evaluation of a quality improvement intervention. American journal of respiratory and critical care medicine. 2008:200802.

67. McCormick AJ CJ, Stowell-Weiss P, Toms C, Engelberg R. Improving social work in intensive care unit palliative care: results of a quality improvement intervention. J Palliat Med. 2010 Mar 2010;13(3):8.

68. Campbell M, Guzman J. A proactive approach to improve end-of-life care in a medical intensive care unit for patients with terminal dementia. Critical Care Medicine. 2004;32(9):1839.

69. Campbell M, Guzman J. Impact of a Proactive Approach to Improve End-of-Life Care in a Medical ICU*. Chest. 2003;123(1):266.

70. Kaufer M, Murphy P, Barker K, Mosenthal A. Family satisfaction following the death of a loved one in an inner city MICU. American Journal of Hospice and Palliative Medicine. 2008;25(4):318.

71. Daly B, Douglas S, O'Toole E, et al. Effectiveness Trial of an Intensive Communication Structure for Families of Long-stay ICU Patients. Chest. 2010.

72. Steel A, Underwood C, Notley C, Blunt M. The impact of offering a relatives' clinic on the satisfaction of the next-of-kin of Critical Care patients--A prospective time-interrupted trial. Intensive and Critical Care Nursing. 2008;24(2):122-129.

73. Medland J, Ferrans C. Effectiveness of a structured communication program for family members of patients in an ICU. American Journal of Critical Care. 1998;7(1):24.

74. Lee Char S, Evans L, Malvar G, White D. A Randomized Trial of two Methods to Disclose Prognosis to Surrogate Decision Makers in ICUs. American Journal of Respiratory and Critical Care Medicine. 2010:201002.

75. White D, Braddock III C, Bereknyei S, Curtis J. Toward shared decision making at the end of life in intensive care units: opportunities for improvement. Archives of internal medicine. 2007;167(5):461.

76. White D, Curtis J, Lo B, Luce J. Decisions to limit life-sustaining treatment for critically ill patients who lack both decision-making capacity and surrogate decision-makers*. Critical care medicine. 2006;34(8):2053.

77. Apatira L, Boyd E, Malvar G, et al. Hope, truth, and preparing for death: perspectives of surrogate decision makers. Annals of internal medicine. 2008;149(12):861.

78. Zier L, Burack J, Micco G, et al. Doubt and belief in physicians' ability to prognosticate during critical illness: the perspective of surrogate decision makers. Critical care medicine. 2008;36(8):2341. 
79. Giacomini M, Cook D, DeJean D. Life support decision making in critical care: Identifying and appraising the qualitative research evidence*. Critical care medicine. 2009;37(4):1475.

80. Kaufman S. And a time to die: How American hospitals shape the end of life: Scribner Book Company; 2005. 